NBER WORKING PAPER SERIES

\title{
U.S HIGH SCHOOL GRADUATION RATES: PATTERNS AND EXPLANATIONS
}

\author{
Richard J. Murnane \\ Working Paper 18701 \\ http://www.nber.org/papers/w18701 \\ NATIONAL BUREAU OF ECONOMIC RESEARCH \\ 1050 Massachusetts Avenue \\ Cambridge, MA 02138 \\ January 2013
}

This paper has been accepted for publication in the Journal of Economic Literature. I am a member of the Board of Directors of MDRC. (Research conducted by MDRC is described in this paper.) I received support from the Russell Sage and Spencer Foundations for some of the research on which this paper is based. The views expressed herein are those of the author and do not necessarily reflect the views of the National Bureau of Economic Research.

NBER working papers are circulated for discussion and comment purposes. They have not been peerreviewed or been subject to the review by the NBER Board of Directors that accompanies official NBER publications.

(C) 2013 by Richard J. Murnane. All rights reserved. Short sections of text, not to exceed two paragraphs, may be quoted without explicit permission provided that full credit, including $\odot$ notice, is given to the source. 
U.S High School Graduation Rates: Patterns and Explanations

Richard J. Murnane

NBER Working Paper No. 18701

January 2013

JEL No. C81,I21,I24,J15,J16,J24,J31

\begin{abstract}
$\underline{\text { ABSTRACT }}$
I survey the evidence on patterns in U.S. high school graduation rates over the period 1970-2010 and report the results of new research conducted to fill in holes in the evidence. I begin by pointing out the strengths and limitations of existing data sources. I then describe six striking patterns in graduation rates. They include stagnation over the last three decades of the twentieth century, significant race-, income-, and gender-based gaps, and significant increases in graduation rates over the first decade of the twenty-first century, especially among blacks and Hispanics. I then describe the models economists use to explain the decisions of individuals to invest in schooling, and examine the extent to which the parameters of the models explain recent patterns in graduation rates. I find that increases in the nonmonetary costs of completing high school and the increasing availability of the GED credential help to explain stagnation in the face of substantial gaps between the wages of high school graduates and school dropouts. I point out that there are several hypotheses, but to date, very little evidence to explain the increases in high school graduation rates over the first decade of the twenty-first century. I conclude by reviewing the evidence on effective strategies to increase high school graduation rates, and explaining why the causal evidence is quite modest.
\end{abstract}

Richard J. Murnane

Graduate School of Education

Harvard University

6 Appian Way - Gutman 469

Cambridge, MA 02138

and NBER

richard_murnane@ harvard.edu 


\title{
U.S High School Graduation Rates: Patterns and Explanations *
}

\author{
1. Introduction
}

"We have one of the highest high school dropout rates of any industrialized nation.... And dropping out of high school is no longer an option. It's not just quitting on yourself, it's quitting on your country—and this country needs and values the talents of every American.”

------President Barack Obama, State of the Union Speech to the U.S. Congress, Feb. 24, 2009

During the first seventy years of the twentieth century, the high school graduation rate of teenagers in the United States rose from 6 percent to 80 percent. $^{1}$ A result of this remarkable trend was that by the late 1960s, the U.S. high school graduation rate ranked first among countries in the Organisation for Economic Co-operation and Development (OECD, 2007). ${ }^{2}$ The increase in the proportion of the labor force that had graduated from high school was an important force that fueled economic growth and rising incomes during the twentieth century.

\footnotetext{
* Harvard University Graduate School of Education. I think the many people made contributions to this paper. Josh Beauregard, Katie Buckley, Stephen Hoffman, Matthew Kraft, David Liebowitz, John Papay, Rachel Rubin, and Melanie Wasserman provided excellent research assistance. David Autor, Robert Balfanz, Carrie Conaway, Janet Currie, David Deming, Greg Duncan, Joanna Fox, Eric Hanushek, James Heckman, Andrew Ho, Kevin Lang, Frank Levy, Lawrence Mishel, Richard Nelson, Phil Oreopoulos, John Papay, Margaret Patterson, Janet Quint, Joydeep Roy, David Stern, Lazar Treschan, Rebecca Unterman, Michael Wald, Rob Warren, and four referees provided helpful comments on earlier drafts of this paper. Claudia Goldin, Sarah Turner, The Massachusetts Department of Elementary and Secondary Education, and the GED Testing Service provided data. Paul LaFontaine answered many questions about the methods he and James Heckman used in estimating the high school graduation rates reported in their 2010 paper. The Russell Sage and Spencer Foundations provided support for some of the research on which this paper is based.

${ }^{1}$ Goldin and Katz (2008) report a U.S. high school graduation rate in 1970 of 77 percent. Heckman and Fontaine (2010) estimate a figure of 81 percent (see Table A.7 in the Supplemental Appendix to their 2010 paper.) The difference between these estimates stems in part from differences in the populations on which the estimates are based and in part from differences in methodology. The estimate for 1970 that Goldin and Katz report comes from dividing the number of people who graduated from high school in 1970 (as reported by schools) by the population of 17-year-olds in that year, including recent immigrants (see U.S. Department of Education (1993)). The Heckman and LaFontaine estimate comes from dividing the number of 20-23-year-olds (excluding recent immigrants) in 1970 who report that they had graduated from high school by the total number of 20-23-year-olds in that year, excluding recent immigrants.

${ }^{2}$ As of 2005, the high school graduation rate among 55-64-year-olds was higher in the United States than in any other OECD country.
} 
Between 1970 and 2000, the high school graduation in the United States stagnated. In contrast, the secondary school graduation rate in many other OECD countries increased markedly during this period. A consequence is that in 2000, the high school graduation rate in the United States ranked thirteenth among nineteen OECD countries (OECD, 2012).

Until quite recently, it appeared that the stagnation of the U.S. high school graduation rate had continued into the twenty-first century. However, evidence from two independent sources shows that the graduation rate increased substantially between 2000 and 2010. This increase prevented the United States from losing further ground relative to other OECD countries in preparing a skilled workforce. But graduation rates in other OECD countries also increased during that decade. As a result, the U.S. high school graduation rate in 2010 was still below the OECD average. ${ }^{3}$

Given the importance of educational attainment and skills of workers to labor market earnings for individuals and economic growth for countries (Goldin and Katz, 2008; Hanushek and Woessman, 2008), it is important to understand the reasons for the three-decade stagnation and for the recent increase in the U.S. high school graduation rate. As I explain in detail below, during the last three decades of the twentieth century, increased requirements for a high school diploma counteracted substantial economic returns to the credential. More difficult to explain are the recent increase, and the striking gender gap, in the graduation rate.

The paper addresses the following four questions:

1. What were the patterns in U.S. high school graduation rates during the last 40 years?

\footnotetext{
${ }^{3}$ The OECD (2012) estimates that the U.S. high school graduation rate increased from 70 percent in 1970 to 77 percent in 2010. The OECD bases its estimates on the Common Core of Data, which is described in Section 2. In 2010, the average upper secondary school graduation rate among OECD countries was 84 percent. In that year, the U.S. high school graduation rate ranked twentieth out of twenty-four OECD countries (OECD, 2012, Table A2.3, p.55). However, this comparison may be somewhat deceptive in that, as reported in Table A2.2 of the OECD publication (2012), the high school graduation rate of the population under age 25 in the United States (77 percent) was equal to the OECD average high school graduation rate for people under age 25 . The explanation is that while a significant number of people complete secondary education after age 24 in some OECD countries, this is not the case in the United States.
} 
2. What are the explanations for these patterns?

3. What are promising strategies for increasing the high school graduation rate?

4. Why haven’t policy evaluations been more useful in guiding efforts to increase the high school graduation rate?

The paper is organized in six sections. Section 2 clarifies methodological issues concerning the measurement of high school graduation rates. Section 3 describes patterns and trends in the high school graduation rates of different groups in the United States. Section 4 describes economic models of teenagers' decisions about whether to remain in high school. Section 5 examines the evidence bearing on explanations for the patterns in high school graduation rates. Section 6 summarizes evidence on the effectiveness of policy interventions aimed at increasing high school completion rates. Section 7 reviews the answers to the four questions addressed in the paper and suggests questions for future research. Unless otherwise noted, when discussing data or results, I am discussing U.S. high school graduation rates only.

\section{Methodological Issues}

This section outlines the three types of data sources-household surveys, the Common Core of Data, and longitudinal data sets — used to estimate high school graduation rates in the United States and the strengths and limitations of each. Estimates of high school graduation rates are sensitive to the choice of data source, in part because of differences in coverage. They are also sensitive to methodological choices about how to use the data from any given source. The section also shows why estimates of the high school graduation rate are extremely sensitive to how the researchers categorize recent immigrants and recipients of the General Educational Development (GED) credential. ${ }^{4}$ These measurement issues are critical to the design of future research.

\footnotetext{
4 This section was informed by the thoughtful discussion of different methods of estimating high school graduation rates contained in Mishel and Roy (2006) and Heckman and LaFontaine (2010).
} 


\section{$2.1 \quad$ Household Surveys}

Researchers have estimated high school graduation rates using household surveys including the Current Population Survey (CPS), the decennial Census of the Population, and the American Community Survey (ACS). They do so by calculating a "status completion rate," defined as "the percentage of individuals in a given age range who are not in high school and who have earned a high school diploma or equivalency credential, irrespective of when or where the credential was earned" (Chapman et al., 2011, p. 2). An important strength of this estimation method is its transparency and insensitivity to the number of years that it took individuals to graduate from high school.

One limitation of the CPS as a data source for estimating the status completion rate is that one individual answers questions pertaining to all members of the household. There is some concern that some respondents may exaggerate the educational attainments of household members (Warren and Halpern-Manners, 2007). A second limitation is that the CPS sampling frame includes only the noninstitutionalized civilian population. Consequently, it excludes people living in group quarters, such as incarcerated individuals and those serving in the military. The Census of Population does include these groups and provides a basis for estimating the degree to which CPS-based estimates are biased by the exclusion of the prison and military populations. The detailed information in the Public Use Microdata Sample (PUMS) from the decennial census also provides a basis for estimating the extent to which CPS-based estimates of the graduation rate are biased by including immigrants who did not attend U.S. high schools.

Of course, a limitation of census data is that the census is conducted only every ten years. In response to this problem, the U.S. Census Bureau created the American Community Survey (ACS), which samples approximately 3 million housing units each year. The ACS does include the military 
and incarcerated individuals in its sampling frame and provides data suitable for estimating the status completion rate for the nation.

\subsection{The Common Core of Data}

Each year the National Center for Education Statistics (NCES), a branch of the U.S.

Department of Education, conducts a census of local educational agencies and schools. The resulting database, called the Common Core of Data (CCD), contains information for each public high school in the country on the number of students enrolled in each grade and the number of students who graduated in the previous year. In principle, the CCD has two related strengths as a data source. First, given that the information comes from the administrative records of individual schools, it should be quite accurate. Second, it should be possible to estimate graduation rates for individual schools, districts, and states from the CCD. In practice, however, the comparability of the information across states and across local jurisdictions is compromised by different definitions and accounting practices (Roy and Mishel, 2008). For example, some states issue high school completion credentials indistinguishable from conventional high school diplomas to students in special programs, some of which prepare students to take the GED examinations. ${ }^{5}$

Inaccuracies in the counts of graduates in the CCD are not the only problem. Another problem stems from the varied paths teenagers take through high school. If no students changed schools during their high school years, if no students were retained in grade, and if no teenagers migrated to the United States, then estimating the four-year high school graduation for a high school, for a state, or for the nation from the CCD would be straightforward: simply divide the number of students who graduated at the end of school year $t$ by the number of students who first enrolled at the beginning of school year, $t$-3. Of course, many students do switch public schools, some move between public and

\footnotetext{
${ }^{5}$ See Heckman, Humphries, LaFontaine, and Rodriguez (2012). In Table F-1 on page 33 of the online appendix, Heckman and his colleagues list ten states that follow this practice.
} 
private schools, some take longer than four years to graduate, and some immigrants enter U.S. high schools as tenth, eleventh, or twelfth graders.

A consequence of these varied paths through high school is that the number of ninth grade students in a state's public schools in a particular year may not be an accurate estimate of the number of students who could graduate from the state's public high schools three years later. A related problem is that the number of students enrolled in the ninth grade in a particular year may not be a good estimate of the number of students who first enrolled in ninth grade in that year because a substantial numbers of students are retained in that grade, as I later illustrate. A result is that dividing the number of students who graduate at the end of year $t$ by the number of students enrolled in Grade 9 in year $t-3$ underestimates the four-year graduation rate. Moreover, since the percentage of ninth grade students retained in grade has risen in recent decades, the bias from estimating four-year graduation rates using this conventional methodology has increased, especially for blacks and Hispanics, groups with especially high retention rates in ninth grade (Roy and Mishel, 2008). Analysts have developed a variety of strategies to account for these issues. For example, in 2006, NCES reported estimates from the CCD of the percentage of high school students who graduated on time using a method known as the "Averaged Freshman Graduation Rate” (AFGR). It calculates the AFGR in year $t$ for individual states and for the nation by dividing the number of graduates with regular diplomas in year $t$ by the average number of students enrolled in Grades 8, 9, and 10, three, four and five years earlier. ${ }^{6}$ Roy and Mishel (2008) conclude that, although some of

\footnotetext{
${ }^{6}$ For a detailed explanation of the method used to calculate the AFGR, see Seastrom et al. (2006). After adopting the AFGR method, NCES applied it to information from the CCD for earlier years. For example, the Digest of Education Statistics 2009 reports estimates of the AFGR for the nation for every school year from 1969/1970 to 2008/2009. See http://nces.ed.gov/programs/digest/d09/tables/dt09_103.asp. However, in a personal communication, Robert Stillwell of NCES pointed out that the estimates for years prior to 2002/2003 may not be comparable with estimates beginning in that year because of changes in the enrollment information provided in the CCD. See Swanson (2003) and Warren and Halpern-Manners (2009) for informative discussions of alternative methods for estimating high school graduation rates from the CCD.
} 
the methods are less biased than others, none produces accurate estimates. ${ }^{7}$ For that reason, I rely primarily on data sources other than the CCD in reporting patterns in high school graduation rates for the nation. However, because until very recently, the CCD was the only data source for estimating high school graduation rates for states and individual schools, I report some patterns in CCD-based estimates that are supported by other data.

Although analysts argue about the merits of alternative estimators of state and national graduation rates based on the CCD, there is no disagreement that estimates of high school graduation rates for schools or districts based on the CCD are too sensitive to student mobility patterns to be used in accountability systems.

\subsection{Longitudinal Data Sets}

A third data source for estimating high school graduation rates for the nation as a whole is the set of longitudinal studies sponsored by NCES and the U.S. Department of Labor. These data sets track the academic progress over time of nationally representative samples of students. An important strength of these data sets is their ability to follow students who change schools and those who take more than four years to complete high school. The data sets also provide a method of estimating high school graduation rates for students enrolled in private schools.

One limitation of using information from the longitudinal surveys is nonrandom sample attrition; individuals who drop out of school are also particularly likely not to respond to follow-up surveys. If these cases are simply dropped from the analysis, the results will likely overestimate high school graduation rates. Another limitation that also risks overestimating graduation rates is that most longitudinal surveys sponsored by NCES (including High School and Beyond and the Education Longitudinal Study of 2002) first sample adolescents when they are in Grade 10. Using data from the

\footnotetext{
${ }^{7}$ A recent report by a National Research Council committee (Hauser and Koenig, 2011) recommends that NCES stop reporting high school graduation rates calculated by applying the AFGR method to data from the CCD.
} 
National Education Longitudinal Study of 1988 (NELS88), which followed a large sample of students who were eighth graders in 1988 to a final survey in 2000, Altonji and Mansfield (2011) report that one-third of the survey participants who dropped out of high school did so before the first follow-up survey in Grade 10. Consequently, these youth would not have been included in longitudinal studies that begin with tenth-grade students. ${ }^{8}$

The relatively young age at which NELS88 participants were first surveyed makes this data set valuable for estimating high school graduation rates. However, as Heckman and LaFontaine point out in the online appendix to their 2010 paper, the NELS88 data set also has limitations. Students who were listed by school administrators as learning disabled or physically disabled did not participate in the survey. Those students, who were disproportionately minority males, had higher school dropout rates than students included in the NELS88 sample. Another limitation is that the survey excluded institutionalized individuals, including those who were incarcerated, from the final survey in 2000. Given that the overwhelming majority of the incarcerated are high school dropouts, excluding them leads to an overestimate of graduation rates of minority males. However, Mishel and Roy (2006) argue convincingly that, even for these groups, NELS88-based estimates of high school graduation rates are more accurate than those based on the CCD.

Administrative databases that track the academic progress of all students attending public schools in a state provide an increasingly important source of information on high school outcomes for students enrolled in public schools. One indication of their importance is that U.S. Department of Education regulations (2008) specify that all states use longitudinal data on individual students to

\footnotetext{
${ }^{8}$ See Barton (2009) and Hauser and Koenig (2009) for informative summaries of problems with alternative strategies for estimating high school graduation rates.
} 
calculate and report four-year cohort graduation rates, disaggregated by subgroups, at the school, district, and state level, beginning with the 2010-11 school year. ${ }^{9}$

In many respects, the longitudinal databases developed by state departments of education are an advance over the CCD. However, the same three atypical student paths through high school that make it impossible to develop accurate estimates of high school graduation rates from the CCD (student mobility, grade retention, and immigration) also make it difficult to achieve this objective using state-specific longitudinal databases. In an attempt to make comparisons of high school graduation rates meaningful, the U.S. Department of Education published a twenty-nine-page set of rules in 2008 that it expects states to follow in calculating high school graduation rates from administrative records. ${ }^{10}$ One rule is that a student who leaves the state's public schools prior to graduation can be dropped from the relevant cohort (the denominator in the high school graduation calculation) only if the school or district obtains "confirmation in writing" that the student enrolled in a private high school, a high school outside the state, emigrated, or died. ${ }^{11}$ A second requirement is that states must report four-year graduation rates. A third is that students entering a public school, even as late as twelfth grade, must be counted in the appropriate cohort in calculating the four-year graduation rate. While the intent of the rules is to specify a common set of practices all states follow in calculating high school graduation rates, there is considerable room for interpretation. For example, does a note from a guidance counselor stating that a student told her he was enrolling in a high school in a neighboring state count as "confirmation in writing”?

To illustrate the importance of the rules and their interpretation, I display in columns 1-7 of Table 1 the set of mutually exclusive possible graduation statuses six years after initially starting

\footnotetext{
${ }^{9}$ The incentive for states to comply with the federal reporting requirement is that, under the No Child Left Behind legislation, states that do not do so could lose federal funding of compensatory education (Title 1) programs.

${ }^{10}$ U. S. Department of Education (2008).

${ }^{11}$ Ibid., p. 9.
} 
Grade 9 for 77,190 students who entered ninth grade in a Massachusetts public school for the first time at the beginning of the 2005/2006 school year. ${ }^{12}$ (Table 1 excludes students who joined this cohort after the fall of 2005.) Column 1 lists the percentage of students in each demographic group known to have graduated from a Massachusetts public high school within four years of initial entry to Grade 9. Column 2 lists the percentage known to have taken five years to graduate. Column 3 lists the percentage known to have taken six years to graduate. Column 4 lists the percentage known not to have graduated. It includes known dropouts, including those who subsequently earned the GED credential, the small number of students who completed twelfth grade but did not receive a diploma, the small number who were still enrolled in high school six years after entering Grade 9, and the few students who died. ${ }^{13}$ Column 5 lists the percentage of students who were recorded in the state database as having transferred out of the state public school system. Column 6 lists the percentage of students who disappeared from the system but did so without an exit code indicating what had happened to them. Column 7 lists the four-year high school graduation rate of each group, calculated using the rules specified by the U.S. Department of Education (2008). ${ }^{14}$

The first thing to notice is that almost 10 percent of black and Hispanic youth who graduate from Massachusetts public schools take more than four years to do so. The comparable figure for

\footnotetext{
${ }^{12}$ The information displayed in Table 1 is based on my analyses of a restricted database provided by the Massachusetts Department of Elementary and Secondary Education. This is the same data base that the Department uses to generate the information on MA high school graduation rates required under No Child Left Behind. I think John Papay for his considerable assistance in conducting the analyses.

${ }^{13}$ Fewer than 1 percent of students in Massachusetts public schools completed Grade 12 but were not awarded a diploma. According to U.S. Department of Education rules, these students must be counted as nongraduates in estimating high school graduation rates. Fewer than 0.5 percent of students in the cohort were still enrolled in a Massachusetts public high school six years after entering Grade 9.

${ }^{14}$ Owing to rounding error, some of the graduation rates reported in column 9 differ slightly from the estimates calculated by dividing the figure in column 1 by (100- the figure in column 7). The U.S. Department of Education rules specify that states should include late entrants to a cohort in calculating the four-year high school graduation rate. Following these rules, the Massachusetts Department of Elementary and Secondary Education calculates the on-time graduation rate for the 2009 cohort to be 81.5 percent. The reason that the estimate of the high school graduation rate that is reported in Table 2 (84.4 percent) is higher than the DESE figure is that the population on which the figures in Table 2 are based excludes late entrants to the 2009 cohort.
} 
white youths is 2 percent. Consequently, racial/ethnic gaps in six-year graduation rates are 15 percent to 25 percent smaller than racial/ethnic gaps in four-year graduation rates.

A second interesting aspect of Table 1 is that the percentages of black and Hispanic students who are listed as transferring out of the Massachusetts public high schools (14.5 and 16.3 percent, respectively) are almost twice as high as the percentage of white students listed as exiting the system (7.9 percent). Individual schools, which are the source of data on student transfers, have strong incentives to list students who leave without a diploma as transfers rather than as simply having disappeared. The reason is that transfers are removed from the cohort in calculating the school's high school graduation rate. Consequently, estimates of high school graduation rates in a state, especially graduation rates of black and Hispanic students, are very sensitive to the interpretation of the "confirmation in writing" rule. For an indication of the importance of transfers, compare the estimates of graduation rates for African-American youth in column 1 and column 7 of Table 1. The estimate in column 7 (72.6 percent) assumes that all of the black students counted as transfers (14.5 percent of the total number of black students) belong in that category. The estimate in column 1 (62.1 percent) assumes that all of these students stopped going to high school after leaving the Massachusetts public school system.

[Table 1 about here]

Another issue in using the state's longitudinal database is how to count students who transfer into a public school after starting high school in another jurisdiction. Among the public school students scheduled to graduate in 2009, there were 7,517 late entrants (8.9 percent of the cohort). Under U.S. Department of Education rules, such students must be included in estimates unless they subsequently transfer out of the state's public school system. Two aspects of the distribution of outcomes for these late arrivals stand out. The first is the small percentage (46.3) who graduate from 
Massachusetts public schools within four years of entry into Grade 9. The second is the remarkably high percentage (29.5) listed as transferring out of the state public school system. The net effect of the large percentage counted as transfers is that the estimated four-year graduation rate for late entrants (65.7 percent), while still low, is 20 percentage points higher than it would be if the transfers had been treated as dropouts. In summary, high school graduation rates are likely to be especially low in states experiencing significant in-migration of students. Just how much in-migration lowers estimates of high school graduation rates will depend a great deal on the classification of the large percentage of in-migrants who leave a state’s public high schools prior to graduation.

How researchers count students who are retained in grade, who transfer out of public schools, and who enter Massachusetts high school late has a substantial impact on graduation rate estimates for individual high schools. To illustrate this, Table 2 provides information on educational outcomes for students in the 2009 graduating cohort of one large urban high school (enrollment greater than 2,000) and one quite large suburban high school (enrollment greater than 1,500) in Massachusetts. The urban high school is located in a community with large numbers of low-income immigrants. More than one-half of the students in the urban high school are non-white, and the majority of students are eligible for free- or reduced-price lunch. In 2011, the number of ninth graders in the school was 60 percent larger than the number of twelfth graders, reflecting both retention of students in Grade 9 and a high dropout rate.

The suburban school also has a substantial number of non-white students, more than onequarter of the total enrollment. However, owing to high housing prices, the percentage of students from low-income families is modest. In 2011, fewer than 10 percent were eligible for free or reduced price lunch. In contrast to the urban high school, the number of twelfth graders in the suburban school was greater than the number of ninth graders. 
The first row of outcomes for each school in Table 2 pertains to students who entered the high school on time as ninth graders in September 2005. The second row pertains to late entrants to the cohort. The column entries have the same definitions as in Table 1. Given the difference in the demographics of the student bodies, it is not surprising that the percentage of on-time graduates among students who entered the urban school at the beginning of Grade 9 (51.3 percent) is much lower than the percentage of four-year graduates among on-time entrants to the suburban school (84.6 percent). The same is true for late-entrants: a 32.8 percent on-time graduation rate for late entrants to the urban school compared with a 72.7 percent rate in the suburban school. Nor perhaps is it surprising that the percentage of the cohort in the urban school serving immigrant communities that consists of late entrants (almost 25 percent) is approximately twice as high as the comparable percentage of late entrants to the cohort in the suburban school.

Most relevant to this paper is the contrast between the two schools in the ratio of transfers to students with unknown outcomes. For example, 44.5 percent of late entrants to the urban school are classified as having transferred. In contrast, only 1.7 percent of late entrants to the cohort in the urban school are classified as having unknown outcomes, meaning that the student left the school prior to graduation but the school does not know what the student did after leaving. Thus, the ratio of the number of students classified as "transfers" to the number classified as "unknown" in the urban school is 26 to 1 . The corresponding ratio of transfers to unknown outcomes for late entrants to the suburban school is less than 2 to 1 .

The most compelling explanation for the difference in these ratios is that the urban school applied a much looser interpretation of the "confirmation in writing" criterion for placing students in the transfer category than did the suburban school. ${ }^{15}$ Because the percentage of students in the 2009

\footnotetext{
${ }^{15}$ To examine the validity of this explanation, we looked to see whether the students reported as having transferred to another public high school in Massachusetts appeared on the rolls of another school. The urban school reported
} 
graduating cohort of the urban high school who left prior to earning a diploma is so high (45.9 percent of on-time entrants and 60.5 percent of late entrants), the strictness with which the school applied the "confirmation in writing" rule in specifying transfers has an enormous impact on the estimated graduation rate for the cohort. ${ }^{16}$

In summary, the Achilles heel in developing accurate estimates of high school graduation rates from state longitudinal databases is the classification of students who disappear from one public high school and do not enroll in another public high school in the same state. States must rely on reports from high schools to classify these students. In the absence of expensive monitoring, schools have strong incentives to classify students who leave prior to graduation as "transfers." To the extent that this does not accurately represent the students' status, this practice results in biased estimates of high school graduation rates. ${ }^{17}$ Consequently, differences among schools, and indeed among states, in estimated graduation rates may reflect different interpretations of the "confirmation in writing" rule rather than differences in the success of high schools in educating students.

[Table 2 about here]

\subsection{Recent Immigrants}

One other factor that influences the estimates of high school graduation rates, especially of Hispanics, is whether recent immigrants are included in the relevant population. Among twenty- to twenty-four-year-olds in the United States in 2010, 8.4 percent were recent immigrants (defined as

that a total of 90 students (19 percent of the total number of “transfers”) moved to another Massachusetts high school. Only 58 of the 90 (64 percent) appeared on the rolls of another Massachusetts public high school. The suburban high school reported that a total of 10 students (22 percent of the total number of "transfers") moved to another Massachusetts public high school. All ten appeared on the rolls of another high school. This pattern supports the explanation that the urban school employed a much more looser interpretation of the "confirmation in writing” rule than the suburban school did.

${ }^{16}$ The percentage of nongraduates in the cohort is calculated by subtracting from 100 the sum of the percentages of the cohort graduating in four, five, and six years since first entering Grade 9.

${ }^{17}$ One way that states, including Massachusetts, are reducing the bias when high schools report students who disappear as transferring to another public school in the state is to verify that the student does appear on the rolls of another high school in the state. However, short of monitoring the quality of the documentation that schools use in declaring a leaving student as a transfer to a school outside of the state, states must accept the classifications provided by individual high schools. 
those who came to the United States after age 11). Of these, 55.8 percent were Hispanic. ${ }^{18}$ The high $^{2}$ school completion rate among twenty- to twenty-four -year-old Hispanics who were recent immigrants is 48.5 percent, considerably lower than the 77.8 percent of twenty- to twenty-four-yearold Hispanics who were not recent immigrants. In contrast, the graduation rate of recent white immigrants of the same age is 90.0 percent, a figure higher than that for whites who are not recent immigrants (86.3 percent). ${ }^{19}$ A consequence of this pattern is that estimates of the Hispanic-white gap in high school graduation rates are much higher if recent immigrants are included. A corollary of this pattern is that high school graduation rates tend to be particularly low in schools and school districts that serve large numbers of recent Hispanic immigrants.

\subsection{The GED}

A controversial question is whether to treat recipients of the GED as high school graduates. The GED was introduced in 1942 as a means of providing a secondary school credential to veterans who joined the military before graduating from high school. In 1947, New York was the first state to allow school dropouts who were not veterans to earn the GED credential. In 1974, California became the last state to offer the GED option (Heckman, Humphries, and Mader 2011).

Whether to count GED recipients as high school graduates is controversial for three reasons. First, average labor market outcomes for GED recipients are much closer to those of dropouts without this credential than to those of conventional high school graduates (Cameron and Heckman, 1993; Murnane, Willett, and Tyler, 2000). Second, the number of GED recipients increased rapidly during the 1990s. In 2011, 433,990 Americans passed the GED examinations, a figure equal to 12 percent of

\footnotetext{
${ }^{18}$ My tabulations from the 2010 ACS.

${ }^{19}$ My tabulations from the 2010 ACS with the estimated number of GED recipients subtracted from the number of high school graduates reported in the ACS. The high school graduation rate among recent black immigrants who were age twenty to twenty-four in 2010 is 82.2 percent. As shown in Table 3, the high school graduation rate of black twenty- to twenty-four-year olds in 2010 who were not recent immigrants is 78.2 percent.
} 
all high school credentials issued that year. ${ }^{20}$ Third, black and Hispanic youth are particularly likely to earn the GED credential instead of a conventional high school diploma. Among those aged twentyfive to twenty-eight in 2008, 17.4 percent of blacks and 12.8 percent of Hispanics who had earned a secondary school credential did so by obtaining a GED. This compares with 10.6 percent of nonHispanic whites. ${ }^{21}$ For all of these racial/ethnic groups, the GED is more common among those born in the early 1980s than among those born a decade earlier. ${ }^{22}$ Consequently, estimates of trends in the high school graduation rates of black and Hispanic youth are particularly sensitive to treatment of the GED credential.

The NCES counts GED recipients as high school completers in its estimates of the status completion rate. However, it does not include GED recipients as high school graduates in its estimates of the average freshman graduation rate for public school students. ${ }^{23}$ This is one reason that estimates of the status completion rate (89.8 percent for those aged eighteen to twenty-four in 2009) are considerably higher than estimates of the AFGR (75.5 percent for the 2008/2009 school year) (Chapman et al., 2011). Another reason is that the 11 percent of U.S. teenagers who attend private schools and the 3 percent who are home schooled are included in the population of young Americans for which the status completion rate is estimated, but not in the population of students attending

\footnotetext{
20 The figure on the number of Americans passing the GED examinations in 2011 comes from GED Testing Service (2012), Table 14. The 12 percent figure is calculated by dividing the number of GED recipients by the sum of the number of Americans passing the GED examinations and the number of high school diplomas awarded in 2011. The number of high school diplomas awarded $(3,282,200)$ is from Snyder and Dillow (2012), Table 111. Since 2004, this percentage has held quite steady at 12 percent. However, as explained later in this paper, the age distribution of individuals passing the GED examinations has changed markedly in recent years. In 2003, 36 percent of those who passed the GED exams were 16-18 years of age. In 2011, the comparable percentage is 27 percent.

${ }^{21}$ My calculations using data from the NLSY97.

${ }^{22}$ For example, among blacks who were in Grade 8 in 1988, and consequently had been born in 1973 or 1974, 15.1 percent of those who had earned a secondary school credential by the age of twenty-six did so by obtaining the GED credential. ${ }^{22}$ For Hispanic youth, the figure is 11.6 percent. The comparable figure for non-Hispanic white youth is 8.4 percent. These estimates are from Ingels et al. (2002), and are based on data from the National Education Longitudinal Study of 1988.

${ }^{23}$ A few states, including New Jersey, count individuals who obtain a GED through in-school programs as high school graduates, even though they have not satisfied conventional credit hour requirements.
} 
public schools for which the AFGR is estimated. Both of these groups have very high graduation rates. $^{24}$

Given that average labor market outcomes for GED recipients are closer to those of high school dropouts lacking this credential than to conventional high school graduates, I adopt the NCES convention of defining the high school graduation rate as the percentage of individuals in a particular group that earned a conventional high school diploma. I also distinguish GED recipients from “uncredentialed” high school dropouts.

\section{Patterns in High School Graduation Rates}

In this section, I describe six striking patterns in high school graduation rates between 1970 and 2010. I use information from two types of sources. The first consists of published reports of graduation rates. The second consists of estimates I made using data from the decennial Censuses of Population, the ACS, the GED Testing Service, the National Longitudinal Survey of Youth (NLSY) 1979 and 1997, and a data set providing longitudinal information on school outcomes for public school students in Massachusetts.

Two prior studies provide valuable guidance in constructing estimates of high school graduation rates from the census, the ACS, and GED Testing Service data. The first is a 2006 study by Mishel and Roy that compares the strengths and limitations of estimates of graduation rates based on different data sources. These authors also describe a method for combining data from the GED Testing Service on the number of individuals who pass the GED battery of examinations each year with data on educational attainments from the U.S. Census to estimate an "adjusted status completion

\footnotetext{
${ }^{24}$ Using data from the 2002 Education Longitudinal Study, Bozick and Lauff (2007) report that the graduation rate for students attending Catholic high schools in 2004 was 98.1 percent. The corresponding figure for students who attended other private high schools was 96.2 percent. These estimates are probably upwardly biased because they only include students who had not left high school prior to the timing of the baseline survey in Grade 10. To my knowledge, there is no clear definition of high school graduation for students who are home-schooled. But presumably, most home school students would report on household surveys that they had "graduated."
} 
rate” in which GED recipients are not included in the number of high school graduates. The second is Heckman and LaFontaine’s 2010 paper showing that many apparent inconsistencies in the evidence on U.S. high school graduation stem from differences across studies in the populations from which survey samples are drawn and from differences in the definition of a high school graduate. These authors refined the Mishel and Roy method and report adjusted status completion rates for cohorts of Americans born from the late 1940s through the late 1970 s. $^{25}$

I report Heckman and LaFontaine’s estimates of high school graduation rates for cohorts born in the periods 1947-1950, 1951-1955, and 1956-1960. For cohorts born after these years, I estimate graduation rates using data from the 1990 and 2000 censuses, the 2010 ACS, and micro-data supplied by the GED Testing Service. ${ }^{26}$ In doing so, I follow the method described by Heckman and LaFontaine (2010), including excluding recent immigrants as they did. ${ }^{27}$ For ease of exposition, I sometimes refer to the high school graduation rate for a particular birth cohort in terms of the year when its graduation rate was measured. For example, I refer to the graduation rate for the cohort born between 1986 and 1990 as the graduation rate of twenty- to twenty-four-year-olds in 2010.

\subsection{Stagnation of the National High School Graduation Rate Between 1970 and 2000}

\footnotetext{
${ }^{25}$ Heckman and LaFontaine provide a lengthy online appendix to their 2010 paper that provides a detailed explanation of their method for estimating high school graduation rates.

${ }^{26}$ Heckman and LaFontaine (2010) report estimates of high school graduation rates for cohorts born between 1961 and 1980. They used the tables from the annual GED Statistical Reports to estimate the number of GED recipients within groups defined by age, race/ethnicity, and gender. However, since the Statistical Reports only report counts by gender, by race/ethnicity, and by age group, and not, for example, separate counts for black females of a particular age, Heckman and LaFontaine had to make a number of assumptions to generate their estimates. The individual-specific data on GED recipients provided by the GED Testing Service allowed me to sharpen their estimates as well as to provide estimates for cohorts born between 1981 and 1985 and between 1986 and 1990 . ${ }^{27}$ Heckman and LaFontaine (2010) defined recent immigrants among twenty- to twenty-four-year-olds as individuals who had immigrated within the last ten years. This meant that twenty-four-year olds in Census 2000 would have been counted as recent immigrants if they had immigrated after age fourteen while twenty-year-olds would have been counted as recent immigrants if they had immigrated after age ten. Given that the key question is whether recent immigrants attended U.S. schools, I defined recent immigrants among twenty- to twenty-four-yearolds in the 1990 and 2000 Censuses(Stillwell, Sable, and Plotts 2011) and the 2010 ACS as individuals who had immigrated when they were older than age eleven.
} 
After increasing rapidly for most of the twentieth century, the high school graduation rate, excluding recent immigrants, peaked at about 80 percent in 1970 (Goldin and Katz, 2008). During the next thirty years, the graduation rate stagnated or fell slightly. As shown in Table 3, the estimated status completion rate for twenty- to twenty-four-year-olds, excluding recent immigrants, was 77.6 percent in 2000. Compositional effects account for at least 75 percent of the difference between the estimate for 1970 and $2000 .^{28}$ As illustrated in Figure 1, high school graduation rates are lower for black and Hispanic youth than for white youth. Excluding recent immigrants, the percentage of twenty- to twenty-four-year-olds who are black or Hispanic almost doubled between 1970 (13.9 percent) and 2000 (26.9 percent). ${ }^{29}$

[Figure 1 about here]

[Table 3 about here]

\subsection{Increase in the High School Graduation Rate between 2000 and 2010}

The U.S. high school graduation rate as estimated from adjusted census and ACS data increased by 6 percentage points between 2000 and $2010 .{ }^{30}$ As illustrated in Figure 1, the rate of increase over the decade was quite steady. The increase in the graduation rate is also evident in estimates based on the CCD. For example, the averaged freshman graduation rate for public school students, as reported by NCES, increased from 71.1 percent for the 1998-1999 school year to 75.5 percent for the 2008-2009 school year. The OECD estimate of the secondary school completion rate

\footnotetext{
${ }^{28}$ The 75 percent figure for compositional effects comes from holding constant the racial/ethnic composition of twenty- to twenty-four-year-olds at its 1970 distribution. If the racial/ethnic composition of twenty- to twenty-fouryear-olds (excluding recent immigrants) is held constant at its distribution in 2000, then the predicted high school graduation for 1970 is 77.2 percent, slightly lower than the estimate in 2000 (77.7 percent).

${ }^{29}$ I calculated these percentages from tables in the online supplement to Heckman and LaFontaine (2010). The figures including recent immigrants are 14.6 percent in 1970 and 30.0 percent in 2000.

${ }^{30}$ The ACS only includes individuals in group quarters starting in 2006. For that reason, I estimated graduation rates for twenty- to twenty-four-year-olds in 2001 through 2005 from estimates I calculated of graduation rates of twentyfive- to twenty-nine-year olds in the ACS samples for 2006 through 2010. I used these same surveys to estimate high school graduation rates for 2006 through 2010. In every case, the estimates are of "adjusted completion rates," meaning that GED recipients are not counted as high school graduates.
} 
for the United States, which is also based on the CCD, is 70 percent for 2000 and 77 percent for 2010 (OECD, 2012). ${ }^{31}$

\subsection{Racial/Ethnic and Socioeconomic Gaps in High School Graduates Rates}

Analyses using all of the major data sets show that the high school graduation rates of black and Hispanic youth are substantially lower than those of white youth. For example, on the basis of adjusted census and ACS data (Table 3), the estimated high school graduation rates of white, black, and Hispanic youth born between 1986 and 1990 (86.3, 78.2, and 77.8 percent, respectively) result in a black-white gap of 8.1 percentage points and a Hispanic-white gap of 8.5 percentage points.

Table 3 also shows that racial/ethnic gaps in high school graduation rates are smaller between groups born in the late 1980s than those born a decade earlier—even though the high school graduation rate of white youth born in the late 1980s is higher than a decade earlier. The reason is that the high school graduation rates of black and Hispanic youth born in the late 1980s are more than 10 percentage points higher those of comparable youth born a decade earlier.

One puzzle is that estimates of black-white and Hispanic-white gaps in graduation rates in the CCD do not show the recent declines that appear in adjusted census and ACS estimates. For example, the black-white and Hispanic-white gaps in high school graduation rates in 2008-2009, estimated by applying the AFGR method to the CCD, are 18.5 and 16.1 percentage points, respectively (Stillwell, Sable, and Plotts, 2011). ${ }^{32}$ One factor contributing to the difference in CCD-based estimates is that the CCD estimates four-year graduation rates. Because much larger proportions of black and Hispanic youth take more than four years to graduate from high school, racial/ethnic gaps in four-year

\footnotetext{
${ }^{31}$ The OECD computes the secondary school graduation rate for the United States by calculating the sum of agespecific graduation rates (i.e., number of graduates of a specific age, as measured in the CCD, dividing by the population at this age).

32 The reported four-year graduate rates for white, black, and Hispanic youth in 2008-2009 are 82.0, 63.5 and 65.9 percent, respectively.
} 
graduation rates are larger than gaps in six-year graduation rates. A second factor is that the increase in Grade 9 retention rates has been particularly great for black and Hispanic youth and, as explained above, this results in a downward-bias in CCD-based estimates of graduation rates for these groups. A third factor is that the population of students in the CCD includes recent immigrants who attended public high schools. This is not the case in Table 3 results. This exclusion has a marked impact on estimates of the size of the Hispanic-white gap given that Hispanics constitute the majority of recent immigrants and they have a very low high school graduation rate. Evidence from nationally representative data sets support the claim that estimates of racial/ethnic gaps in graduation rates based on the CCD are upwardly biased. For example, the estimates from the NLSY97 of the black-white gap and Hispanic-white gap in graduation rates among twenty-five to twenty-eight-year olds are 11.4 and 8.9 percentage points, respectively. ${ }^{33}$ These estimates are much closer to those derived from adjusted ACS data than from those based on the CCD.

Although they receive less attention than race-based gaps, youth from low socioeconomic status (SES) families, as measured by the incomes and educational attainments of parents, have considerably lower graduation rates than those from higher SES families. For example, among eighth-grade students in 1988, the graduation rate is 31 percent lower for children in the lowest SES quartile than children in the top quartile (Ingels et al., 2002). This pattern is troubling given the role education plays in upward mobility.

\subsection{A Gender Gap Favoring Females}

The high school graduation rate is higher for females than for males in each of the major racial/ethnic groups, but particularly for black youth (12.2 percentage points among twenty- to twenty-four-year-olds in 2010, as measured from adjusted ACS data). As Goldin and Katz (2008)

\footnotetext{
${ }^{33}$ My calculations from the NLSY97.
} 
point out, the gender gap in high school graduation rates is not a new pattern. Throughout most of the twentieth century, more females than males graduated high school. ${ }^{34}$

During the first decade of the twenty-first century, gender gaps in graduation rates fell, especially among Hispanics, even though graduation rates for females in all of the major racial/ethnic group increased. The reason is that the graduation rates of males, especially Hispanics, experienced greater increases (see Table 3). Yet even with these increases, significant gender gaps prevail, especially among black and Hispanic youth.

As Martha Bailey and Susan Dynarski (2011) point out, gender gaps in educational attainments are more difficult to explain using conventional economic models than gaps based on SES or race because males and females grow up in the same families and attend the same schools. Nor are gender gaps unique to the United States. Among twenty-six OECD countries, the gap favoring females was at least 4 percentage points in twenty-two of the countries in 2010, with an average gap of 6 percentage among the reporting countries (OECD, 2012).

\subsection{Concentration of the Dropout Problem in A Small Subset of High Schools}

High school dropouts tend to be concentrated in certain schools. In 2008, one-half of all high school dropouts attended one of the 1,746 high schools with high dropout rates (in which the number of students enrolled in twelfth grade in a particular year was less than 60 percent of the number enrolled as ninth graders three years earlier). These schools overwhelmingly enroll black and Hispanic students from low-income families. The majority are located in cities, but almost one-third are in rural areas and towns, primarily in the South. ${ }^{35}$

\footnotetext{
${ }^{34}$ In 1920, the gap was 7 percentage points; in 1950, it was 5 points. During the next twenty years the gap narrowed, and by 1970, the graduation rates of twenty- to twenty-four-year-old males and females were approximately equal. However, between 1970 and 2000, the gender gap would widen again.

${ }^{35}$ These schools constituted 14 percent of the nation's 12,074 public high schools enrolling at least three hundred students. I thank Robert Balfanz for providing the number of high schools with enrollment of at least three hundred students in 2008 and also information on the location of the high schools with very high dropout rates. Balfanz and his colleagues base their estimates on information from the CCD. At this point, it is not possible to determine to what extent
} 


\subsection{Variation among States}

National trends in high school graduation rates conceal significant variation among states. For example, the average freshman graduation rate in 2008-2009 ranged from a low of 56.3 percent in Nevada to a high of 90.7 percent in Wisconsin. In the six years between the 2002-2003 and 20082009 school years, the average freshman graduation rate rose by at least 3 percentage points in seventeen states, and fell by at least 3 points in three states. Robert Balfanz and his colleagues (2012) conclude that the increase in twelve states between 1999 and 2009 accounted for most of the increase in the national high school graduation rate over this period.

Part of the variation among states in graduation rates and trends reflects variation in the racial/ethnic composition of high school students. For example, the low graduation rate for black youth in Mississippi in 2008-2009 (58.6 percent) had a marked impact on the overall state graduation rate because nearly one-half of all public school students are black. In contrast, the quite low graduation rate for black youth in Wisconsin (65.3 percent) had relatively little impact on the state's overall graduation rate because fewer than 10 percent of the state’s students are black. However, much of the variation among states in high school graduation rates reflects variation in the graduation rates of students of particular race/ethnicities. For example, the 2008-2009 high school graduation rate for black youth was 56.4 percent in Indiana and 71.8 percent in Maryland. ${ }^{36}$

\section{Models of the Decision to Stay in School and Graduate}

\footnotetext{
the patterns reported by Balfanz and his colleagues (2010) are sensitive to the limitations of the CCD reported in Section 2.

${ }^{36}$ All of the estimates of high school graduation rates reported in section 3.6 are from Stillwell, Sable, and Plotts (2011). The estimated graduation rate for black students in Arizona in 2008-2009 (78.7 percent) was even higher than the comparable rate in Maryland. However, the extraordinarily high year-to-year variation in the estimated overall graduation rates for Arizona raises questions about the accuracy of the estimates in that state.
} 
Researchers from several social science disciplines have studied teenagers’ decisions about whether to persist in high school to graduation. Sociologists tend to emphasize the roles of peer groups and school cultures (e.g., Coleman and Hoffer, 1987). Many psychologists have examined teenagers’ decisions from a developmental perspective, recently enriched by evidence from neuroscience on brain development and the attraction of risk-taking during the early teenage years (e.g., Steinberg, 2010). Ethnographers from both of these disciplines point out that for many youth, dropping out is a process rather than an explicit decision. The process starts with irregular attendance, followed by failed courses, and eventually to the realization that the obstacles to graduation are overwhelming (Alexander, Entwistle, and Horsey, 1997; Lyche, 2010; Rumberger, 2011). In contrast to these perspectives, economists typically focus on factors that affect the benefits and costs teenagers face in deciding about whether to remain in school .

\subsection{A High-School Focused Rational Investment Framework}

Most economic models posit that high school students are rational agents whose decisions about whether to stay in school for another year depend on weighing the expected benefits and costs. Critical variables in these models include:

- The predicted payoff over a lifetime (in terms of consumption or utility, which depends on income and nonpecuniary factors such as health) from completing another year of schooling,

- The opportunity cost of continuing in school for another year,

- The rate of time preference (in the absence of perfect capital markets),

- The nonmonitory cost of completing another year of schooling.

- The availability and value of alternative high school completion credentials.

This basic analytical framework dates back to the work of Becker (1964) and Mincer (1958). In recent decades, economists have extended it in important ways. Lang and Ruud (1986) posit that 
the student's decision about whether to stay in school for another year depends on his or her assessment of whether doing so will result in an additional year of completed schooling. One reason it may not is that in many school systems failure to obtain passing grades in core subjects such as English and mathematics results in grade retention. As I discuss in section 5, this extension is important in reconciling the evidence on school dropout rates with evidence from compulsory schooling studies.

Another important extension is to model educational investments as a series of decisions that depend on an individual's cognitive and socioemotional skills. In a number of papers, Heckman and colleagues do this by formulating and estimating models of sequential decisions made at each age and grade (see Cameron and Heckman, 1998, 2001; Cunha and Heckman, 2007, 2008; Cunha, Heckman, and Schennach, 2010; Heckman, Lochner, and Todd, 2006, 2008; and Heckman, Stixrud, and Urzua, 2006). ${ }^{37}$ In these models, skills are determined by the interaction of genetic and environmental influences and are affected by investments made at different stages of childhood. The researchers show that investments in the early years of childhood are particularly important to the development of skills as a result of the biology of brain development. ${ }^{38}$ Children in whom early investments are not made reach high school lacking the skills to make regular progress toward graduation. For these children, the probability that an additional year in school will result in an increase in educational attainment is low, explaining why such a high percentage of students who enter high school with weak skills drop out before graduation.

One insight from the models developed by Heckman et al. is that to understand why a great many students, particularly black and Hispanic students from low-income families, do not graduate from high school, it is important to understand the factors, particularly low income and liquidity

\footnotetext{
${ }^{37}$ Eckstein and Wolpin (1999) also develop and estimate a sequential choice model. While the dynamic selection models are consistent with the rational investment framework, they do not impose it.

${ }^{38}$ For an accessible explanation of the brain development evidence, see Nelson and Sheridan (2011).
} 
constraints, that limit the investments parents can make during the first years of their children's lives. A second insight is that social interventions made during children's early years that supplement the investments parents make in their children will be more efficient than interventions made when children are older.

Yet another extension consists of the insight that the rational investment framework for understanding the schooling decisions of teenagers is consistent with a market signaling model as well as with the more conventional human capital model. For example, Betts (1998) shows that, in the context of his market signaling model, individuals who would have dropped out of school before graduation benefit from a policy intervention that raises the standard for high school graduation. ${ }^{39}$ Building on this work, Bedard (2001) shows that in a human capital model, expansion of access to postsecondary education does not decrease the incentive for marginal high school students to drop out of school. In contrast, in her market signaling model, it increases the incentive to drop out because expansion of postsecondary education dilutes the average quality of the pool of high school graduates who do not go to college. In turn, this reduces the earnings differential between high school graduates and dropouts. She presents evidence supporting the relevance of the signaling model for explaining the decisions of some teenagers to drop out of high school.

\subsection{A Challenge to the Rational Investment Framework}

In the rational investment framework described above, the rate of time preference plays an important role under the realistic assumption that teenagers face credit constraints. Conventional economic models of investment decisions assume that the rate of time preference is constant in the steady state. However, age-sensitive rates of time preference, especially a high rate for many

\footnotetext{
${ }^{39}$ As Lang (2007) explains, the critical question in understanding the consequences of an increase in high school graduation standards concerns the responses of students who, in the absence of an increase in effort, would have graduated under the low standards regime, but not under the high standards regime. Betts and Costrell (2001) describe a model that contains elements of both market signaling and human capital formation. They explain that the policy challenge is to design policies that create incentives for marginal students to increase their effort levels.
} 
teenagers, could explain the apparently irrational decision to drop out of high school and later to regret having done so. A very high rate of time preference for adolescents, especially in the presence of peers, is consistent with recent evidence from neuroscience on the behavior of teenagers (Steinberg, 2010). However, as Frederick, Loewenstein, and O’Donoghue point out in a paper published in this journal in 2002, the concept of age-sensitive rates of time preference really means that the emphasis in the conventional economics framework on long run costs and benefits does not work well as the basis for explaining the schooling decisions of many teenagers. ${ }^{40}$ An implication is that understanding the schooling decisions of teenagers may require especially close attention to the social environment in which they make decisions.

\subsection{A Model of Schooling Decisions with Peer Group Influences}

Drawing on insights from sociology and psychology, Akerlof and Kranton $(2000,2002)$ present a model of schooling decisions in which peer group norms play an important role in determining the nonmonetary cost of skill acquisition and school completion. In the Akerlof and Kranton model, teenagers derive utility from their identity at the time, that is, by how they are perceived by their social group. This, in turn, depends on the ideals of the social group and on the extent to which an individual's attributes and behaviors fit the ideals of the group. For individuals whose social group is the "nerds," their peers value time and effort devoted to acquiring academic skills. For members of this group, the disutility of acquiring the academic skills needed to progress toward graduation is low. For members of the "jocks" social group, athletic prowess is the valued attribute, and the disutility from devoting time and effort to academic skill acquisition is higher. Finally, "burnouts" value opposition to their particular school. For members of this group, the disutility from devoting time and effort to acquiring academic skills is extremely high. Consequently,

\footnotetext{
${ }^{40}$ In the traditional economics framework, the investment decisions of individuals are influenced by the decisions of others only indirectly through impacts on prices.
} 
this is the group with the lowest probability that an additional year spent in school results in an increase in the number of years of completed schooling. ${ }^{41}$

In Akerlof and Kranton's model, schools play an active role in determining the percentage of students who are "burnouts," and consequently are highly unlikely to devote considerable effort to acquiring academic skills. They do this by conveying values, either explicitly or implicitly, that students embrace, tolerate, or actively oppose. Schools with quite homogeneous student populations find it relatively easy to convey a set of values that most students accept, and thus the percentage of burnouts is low. However, with a diverse student population, any single set of values will be opposed by a significant number of students, and this burn-out group is particularly likely to either drop out of school or devote very little effort to fulfilling graduation requirements. As the authors explain, a common response to this problem is to create "shopping mall" high schools, in which there is no driving set of core values. An advantage of the shopping mall school is that almost all students can find a way to identify with some piece of it. ${ }^{42}$ A disadvantage is that the lack of a driving mission means that for all students except for those in the "nerd” group, there is little pressure to excel academically. For most students, a lack of academic pressure was not a major obstacle to graduation when requirements for obtaining the credential were low. However, it has posed more of an obstacle in recent decades as states have responded to the weak skills of many high school graduates by increasing course completion requirements and by introducing exit examinations in core subjects that students must pass.

The Akerlof and Kranton model has implications for the effectiveness of particular uses of resources devoted to improving schooling. One is that using resources to develop a clear sense of

\footnotetext{
${ }^{41}$ Austen-Smith and Fryer (2005) also present a model in which peer groups influence the school-related decisions of adolescents. In their model, many students face a two-audience signaling quandary: the behaviors that promote academic success are the same behaviors that bring about peer-group rejection.

${ }^{42}$ For a rich description of the "shopping mall high school," see Powell, Farrar, and Cohen (1985).
} 
mission that students endorse will improve academic achievement and the graduation rate. A second is that traditional uses of resources that do not address the challenge of building a community will not make a difference. As I discuss in section 6, some of the recent evidence on the effectiveness of alternative strategies to improve high schools is consistent with the predictions of the Akerlof and Kranton model.

Another perspective that emphasizes the importance of the decision-making environment is the behavioral economics view of poverty. The relevance here is that teenagers from low-income families are vastly overrepresented among school dropouts. Bertrand, Mullainathan, and Shafir (2004) and Banerjee and Duflo (2011) argue that the poor are no more or less rational than more affluent individuals. However, the constraints imposed by poverty make mistakes like irregular school attendance more costly for low-income teenagers than for those whose parents have the resources and knowledge to limit the consequences of poor decisions. This perspective leads the authors to focus on situational factors that may encourage good decisions. Rapid responses by school staff to student absences are one example. A second is the creation of small theme-based high schools. The logic is a high school in which all students are expected to do the same work will foster social groups in which paying attention to schoolwork is the accepted norm. In section 6 I describe evidence supporting the value of this perspective.

\section{Explaining the Patterns}

There is a vast literature describing the backgrounds of students who tend to drop out of high school. Correlated characteristics include low family income, low educational level of parents, living in a single-parent household, minority group status, and gender. There are also many papers describing behaviors and attributes of students that predict a relatively high probability of dropping out of high school. They include poor attendance and low test scores in middle school, and having 
repeated a grade (see the many references in Rumberger, 2011). A smaller, but still substantial,

literature describes high schools with relatively high dropout rates (e.g., Balfanz et al., 2010).

Correlated predictors include high rates of teacher turnover and high rates of student suspensions. The descriptive studies do not provide causal evidence to explain the stylized facts described in section 3. The number of studies with designs that support causal inferences is vastly smaller. It is these causal studies that I focus on here.

\subsection{The Predicted Payoff Over a Lifetime from Completing Another Year of Schooling}

As illustrated in the left panel of Figure 2, the average real wages of male school dropouts and male high school graduates have followed similar paths since 1979, declining by more than 15 percent between 1979 and 1993, and recovering about half of the loss over the subsequent sixteen years. ${ }^{43}$ During the same three decades, the average real wage of four-year male college graduates increased by 14 percent. The ratio of the average real wage of dropouts relative to that of terminal high school graduates was at its peak for males in $1980(.80)$ and ranged between .75 and .79 in subsequent years. Thus, the average economic payoff to a high school diploma has risen for males in recent decades, even without taking into account the rising option value of college enrollment that

\footnotetext{
${ }^{43}$ The figures in the panels of Figure 2 are based on my tabulations using the CPS Outgoing Rotation Groups 1979-2009. The sample includes workers aged sixteen to sixty-four who were in engaged in full-time, full-year work, defined as at least thirty-five hours per week for at least forty weeks in the year. The data are first aggregated into sex-age-educationrace/ethnicity cells (two sexes, four age groups, five education groups, and three race/ethnicity groups) using CPS sample weights. In the classification of race/ethnicity, note that Hispanic origin takes precedence over the racial classification where there is a conflict. The composition-adjusted mean hourly wage for each group represented in the figures is the weighted average of the relevant cells, using a fixed set of weights equivalent to the group's average employment share between 1979 and 2009. In these tabulations, it was necessary to treat GED recipients as high school graduates. Because GED recipients earn less, on average, than demographically similar conventional high school graduates, the patterns described in the text and illustrated in the panels of Figure 2 are underestimates of the average wage differentials between school dropouts and conventional high school graduates. In analyzing the impact of immigration on wage inequality using Census and ACS data, Card (2009) was also compelled to treat GED recipients as high school graduates. An interesting question is whether his conclusion that workers with less than a high school education are perfect labor market substitutes for terminal high school graduates would be different if he had been able to distinguish GED recipients from conventional high school graduates.
} 
was available to most high school graduates but typically not to school dropouts. ${ }^{44}$ As many authors have documented, the increase in education-related wage differentials, particularly during the 1980s, stems to a large extent from changes in the economy that increased the demand for particular skills during a period in which the supply of workers possessing the relevant skills grew relatively slowly (See, e.g., Goldin and Katz, 2008; Autor, Levy, and Murnane, 2003; and Autor, Katz, and Kearney, 2008). ${ }^{45}$

Although the real wage trends for females are slightly different, the trend in the average payoff to high school graduation is similar, if more pronounced. As shown in the right panel of Figure 2, the average real wage of female terminal high school graduates was remarkably constant between 1979 and 1997 and then increased by approximately 10 percent over the subsequent twelve years. The average real wage for female dropouts declined by 10 percent between 1979 and 1995, and then recovered over the next fourteen years. The net result is that the ratio of the average real wage of female dropouts to that of terminal high school graduates fell by 6 percentage points (from .83 to .76) over the thirty-year period from 1979 to 2009.

Moreover, the pattern of a declining average real wage of dropouts relative to that of terminal high school graduates is also evident for black males and females and for Hispanic females (see Figure 3).$^{46}$ In a formal analysis that takes into account costs as well as education-related earnings differences, Heckman, Lochner, and Todd $(2006,2008)$ show that the internal rate of return to high school graduation rose between 1960 and 2000 for both white and black youth. ${ }^{47}$

[Figures 2 and 3 about here]

\footnotetext{
${ }^{44}$ As documented in Patterson et al. (2010), about 40 percent of school dropouts who earned the GED credential in 2003 had enrolled in postsecondary education or training institutions by 2009. The vast majority had enrolled in programs lasting no longer than two years. By 2009, fewer than 12 percent of those GED-holders who had enrolled in a postsecondary education or training program had completed it.

${ }^{45}$ For a somewhat different perspective on the explanation for the wage trends, see Lemieux (2008).

${ }^{46}$ The one exception is Hispanic males for whom the relative wage of dropouts increased during the prior fifteen years after dropping for the previous fifteen before that.

${ }^{47}$ These estimates assume a constant discount rate and no psychic costs of school attendance.
} 
A consequence of these wage trends is that, all else being equal, the high school graduation rate should have increased during the prior three decades. So why didn’t it? One possible explanation is that wage trends based on data from the CPS do not provide the relevant expected real wages for adolescents on the margin of dropping out of school. In particular, many teenagers who drop out may correctly perceive that, as a result of their low cognitive skill levels or unproductive behavioral characteristics, they are unlikely to earn much more as a high school graduate than they would as a dropout. The decline in the employment-to-population (EPOP) ratios for high school dropouts aged sixteen to thirty-nine in Figure 4 is consistent with this explanation. Notice that between 1980 and 2007, the EPOP ratio declined by 10 percentage points for male dropouts and by 3 percentage points for female dropouts. ${ }^{48}$ A result of this trend is that the average real wage of employed high school dropouts relative to that of employed terminal high school graduates may be an increasingly biased indicator of the economic payoff to a high school diploma for teenagers with weak skills. $^{49}$

[Figure 4 about here]

Eckstein and Wolpin (1999) present evidence from a structural model fitted with observational data that supports this position. They show that, among white males who were in ninth grade in the early 1980s, those who failed to graduate from high school had lower academic skills and lower motivation (at least for school work) than those who did graduate. An explanation for the

\footnotetext{
${ }^{48}$ Figure 4 is based on CPS Outgoing Rotation Groups 1979-2009. The population sample includes all persons aged sixteen to thirty-nine, excluding those in the military. The employment sample includes all persons aged sixteen to thirty-nine who reported having worked last year, excluding those in the military. Each year depicted in the figure represents a three-year moving average. In describing changes in the EPOP ratio, I used 2007 as the end-point rather than 2008 to minimize the impact of the severe recession that began at the end of 2007.

${ }^{49}$ As Neal (2004) and Mulligan and Rubinstein (2008) have documented, trends in the labor force participation rates for females with particular educational attainments are somewhat different from those of men. They also differ by race and have changed over time. However, as with males, a consequence of trends in EPOP ratios for females is that changes over time in education-related differences in the average real wages of those who work in the formal labor market may not provide unbiased estimates of the economic payoff to high school graduation for women with weak academic skills.
} 
stagnation of the high school graduation rate consistent with the Eckstein and Wolpin evidence is that by the early 1970s, the four out of five students who entered high school with the skills and behavioral traits necessary to benefit from a high school diploma were receiving one. The one in five teenagers with very weak academic skills and/or behavioral tendencies not attractive to employers would not benefit much from a high school diploma, at least given the current "shopping mall” structure of most American public high schools.

Evidence that could challenge the Eckstein and Wolpin explanation comes from studies showing that compulsory school laws requiring adolescents to stay in school longer than they desired resulted in substantial increases in their lifetime earnings. For example, Angrist and Krueger (1991), Acemoglu and Angrist (2001), and Oreopoulos (2007) find that that the labor-market payoff to adolescents compelled to remain in school for an additional year and who consequently complete an additional year of schooling is approximately 10 percent. Of particular relevance, Oreopoulos (2009) takes advantage of relatively recent changes in compulsory school laws in states to estimate the causal impact of additional schooling on subsequent labor market outcomes. He finds that completing an additional year of schooling lowers the probability of subsequent unemployment by 2.2 percentage points and increases weekly earnings by 10.8 percent for white youth. Thus, the evidence indicates that completing additional schooling not only paid off historically for adolescents on the margin of dropping out of school, but also for those in recent decades as well. ${ }^{50}$

One way to reconcile the Eckstein and Wolpin view is to recognize that the results of the compulsory schooling studies are estimates of local average treatment effects that pertain to individuals who completed more years of schooling as a result of the laws. The estimates do not provide information on the benefits of remaining in school for students who do not increase their

\footnotetext{
50 The compulsory schooling studies based on data from the middle decades of the twentieth century do not differentiate by racial/ethnic group.
} 
years of completed schooling even though the law compels them to remain in school for an additional year. This is the case for students who fail to pass the core courses required to progress to the next grade level. Oreopoulos (2009) documents that this pattern is particularly prevalent for black youth. Although laws compelling sixteen-year-olds to remain in school for an additional year increased by 0.16 years the average number of years of schooling that white teenagers complete, they had no impact on the number of years of schooling black teenagers completed.

I illustrate these patterns with data from Massachusetts. As indicated in Table 4, 21 percent of black students and 24 percent of Hispanic students who first entered ninth grade in a Massachusetts public high school in the 2005-2006 school year repeated the grade. This compares with 6 percent of white students. ${ }^{51}$ The percentage of repeaters in each racial/ethnic group is higher for males than for females, with the differences by gender particularly large for black and Hispanic students.

Table 4 illustrates that for substantial fractions of black, Hispanic, or low-income urban students, enrolling in high school for an additional year does not result in an additional year of completed schooling. The results of the compulsory schooling studies do not pertain to these students. ${ }^{52}$ As indicated in column 2 of Table 2, only 35 percent of ninth grade repeaters in Massachusetts graduate from a public high school in the state within six years of entering high school. ${ }^{53}$ Thus, for students compelled to repeat Grade 9, the decision to drop out of high school may reflect a realization that further attendance is unlikely to result in a high school diploma.

\footnotetext{
${ }^{51}$ The definition of "repeated grade 9" is that the student was registered in grade 9 in the fall term after the student was initially in grade 9 . Some of these students were able to move to grade 10 status by the spring term.

${ }^{52}$ One way to understand this point is to view the increase in the minimum school-leaving age as an exogenous event designed to increase the number of years of schooling students complete. Students who do not increase their number of years of completed schooling when subject to the law are noncompliers with the exogenous treatment. Consequently, the local average treatment effect estimate of the impact of an additional year of completed schooling on subsequent labor market earnings does not pertain to them.

${ }^{53}$ Twenty-seven percent of the students who repeated Grade 9 in a Massachusetts public high school were listed in the state database as "transferring" out of the state public school system. Some of these students may have graduated from high school in another state or country. However, as explained in section 2, schools have an incentive to report students who leave their school without a diploma as "transfers."
} 
[Table 4 about here]

In summary, one important reason the high school graduation rate did not increase during the final three decades of the twentieth century despite a high internal rate of return to a high school diploma is that a substantial proportion of students reach high school without the skills needed to complete graduation requirements. As I explain below, increases in graduation requirements contribute to the nonmonetary cost of earning a high school diploma, particularly for teenagers entering high school with weak skills. I also return below to the puzzling question of why, after thirty years of relative stagnation, the high school graduation rate increased during the first decade of the twenty-first century.

To examine the extent to which black-white and Hispanic-white gaps in graduation rates can be accounted for by attributes of individuals measured prior to high school entry, I fit a set of linear probability models predicting high school graduation. The baseline model includes race/ethnicity and gender indicators and their interactions as covariates. I then sequentially add indicators of family socioeconomic status, Grade 8 attendance, and scores on the Grade 8 state mathematics test as covariates. As illustrated in Figure 5, the results show that racial/ethnic gaps in graduation rates can to a large extent be accounted for by skills, behaviors, and family attributes measured when youth were in eighth grade. For example, consider the 14.6 percentage point gap between the six-year high school graduation rates of black males and white males who first entered ninth grade in a Massachusetts public school in September $2005 .^{54}$ Controlling for low family-income status as indicated by eligibility for a free or reduced price lunch reduces the magnitude of the gap to 10.4 percentage points. Adding a control for Grade 8 attendance reduces the gap to 8.6 points. Finally, adding a control for the Grade 8 mathematics score reduces the gap to 4.3 percentage points. Thus, the three control variables account for 71 percent of the gap in graduation rates between black and

\footnotetext{
${ }^{54}$ The sample is restricted to students who took the Massachusetts grade 8 mathematics examination.
} 
white males. Among females, the three control variables play an even larger role, accounting for all of the black-white gap in six-year graduation rates. The same three control variables account for 56 percent of the 20.6 percentage point gap between Hispanic and white males, and 71 percent of the 16.2 percentage point gap between Hispanic and white females. The pattern illustrated in Figure 5 is consistent with the argument made by O’Neill (1990), Neal and Johnson (1996) and Heckman (2011) that differences in childhood investments play a major role in accounting for racial/ethnic gaps in educational attainments and labor market outcomes.

[Figure 5 about here]

There is little question that racial discrimination plays a much smaller role today in explaining differences in labor market outcomes between white and non-white workers than it did fifty years ago. However, Bertrand and Mullainathan (2004) present recent evidence of labor market discrimination against black job applicants. By reducing incentives for black youth to acquire skills and educational credentials, labor market discrimination may contribute to the black-white gap in high school graduation rates. However, its role is modest compared with that of differences in skills evident as early as the beginning of kindergarten.

Recent papers provide a different, but related explanation for the large gender gap in high school graduation rates among blacks and Hispanics. Changes in judicial policies, particularly those related to treatment of drug offenses, have led to a large increase in the incarceration rate of minority males (Alexander, 2012). To my knowledge, there is no causal evidence on how this disturbing trend affected the high school graduation rate of minority males and their children. However, Mechoulan (2011) and Charles and Luoh (2010) present evidence that one of the responses of black and Hispanic females to the judicial policies that reduced the number of marriageable men has been to increase their educational attainments. 
Evans, Garthwaite, and Moore (2012) provide evidence to explain why the high school graduation rate of black males, after increasing for several decades, fell between 1986 and $1996 .{ }^{55}$ They show that the arrival of crack increased the murder rate, the incarceration rate, and the opportunity for employment outside the formal sector for black males. All of these factors contributed to a decline in the rate of return to schooling for black males. While crack did not disappear from American cities by the end of the century, it ceased to have a large impact on the graduation rates of black males because stabilization of markets reduced homicide rates markedly. ${ }^{56}$

\subsection{The Opportunity Cost of Continuing in School For Another Year}

The boom in the demand for Appalachian coal in the 1970s and a subsequent large decline during the 1980s provided substantial variation in the wages available to teenagers in that region. Black, McKinnish, and Sanders (2005) use this natural experiment to examine the impact of opportunity cost on high school graduation rates. They find that a 10 percent decrease in the earnings of low-skilled workers increased the high school enrollment rate by 5 percent to 7 percent. Extrapolating from these results, economic models would predict, all things equal, that the decline in the median real hourly wage of high school dropouts between 1979 and 2000 (Figure 2) would have increased the high school graduation rate. However, as shown in Table 3, this did not occur. Moreover, as shown in Figure 4, EPOP rates for male high school dropouts declined over this period, indicating that increased work effort in the formal labor market cannot explain why high school graduation rates stagnated between 1979 and 2000.

Nor can trends in labor market opportunities for high school dropouts explain the increase in the high school graduation rate between 2000 and 2010. As illustrated in Figure 2, the real wage of

\footnotetext{
${ }^{55}$ The decline in the high school graduation rate that provides the focus of the analysis by Evans, Garthwaite, and Moore (2012) can be seen in Table 3. Notice in that table that the high school graduate rate of the cohort of black males born between 1976 and 1980 is lower than that of cohorts born just earlier or just later.

${ }^{56}$ Fryer et al. (in press) present evidence supporting the findings of Evans, Garthwaite, and Moore (2012).
} 
both male and female dropouts increased during the first part of the decade. But instead of falling, the high school graduation rate increased and continued to increase during the latter part of the decade. The fact that the increase in the graduation rate for males and females began well before 2007 also indicates that the deep recession that began at the end of that year cannot explain why the high school graduation rates of twenty- to twenty-four-year-old males and females were considerably higher in 2010 than the rates for their counterparts born a decade earlier.

\subsection{The Rate of Time Preference}

In the absence of access to credit markets, individuals with high rates of time preference will find educational investments less attractive than those with lower rates of time preference who face the same streams of expected costs and benefits. Thus, in theory, differences in the distribution of time preferences among successive cohorts of teenagers could help explain trends in high school graduation rates. However, to my knowledge, there is no time-series evidence on changes in the distribution of time preference among teenagers. Consequently, evidence on time preferences could only explain differences in high school graduation rates among groups of teenagers with different characteristics.

There is a little evidence from experiments on differences in rates of time preferences among groups of teenagers with different characteristics. For example, Castillo et al. (2011) asked a large group of eighth graders a series of questions about whether they would prefer $\$ 49$ one month from now or a larger amount seven months from now. The responses indicate that black teenagers have higher rates of time preference than white teenagers, and that boys have higher rates than girls. ${ }^{57}$ These authors also show that students with high estimated rates of time discount were more likely to be sent to the school office for a disciplinary infraction over the next year than students with lower

\footnotetext{
${ }^{57}$ Bettinger and Slonim (2007) also report that boys have higher rates of time preference, on average, than girls.
} 
rates of time discount. This is relevant because disciplinary infractions are negative predictors of the probability of high school graduation. Thus, the evidence presented by Castillo and his colleagues is consistent with the argument that differences in time preferences explain at least part of the difference between the high school graduation rates of black and white teenagers and those of male and females.

Lang and Ruud (1986) attempt to evaluate how important differences in time preference are in explaining the black-white gap in high school graduation rates relative to differences in perceived costs and benefits. Like Castillo and his colleagues, Lang and Ruud find higher rates of time preference for black teenagers, but these higher rates do not explain educational attainment differences. Instead, the attainment difference stems primarily from the longer time it takes for black students to complete high school.

Although theoretically interesting, the distinction between differences in rates of time preferences and nonmonetary costs of acquiring a high school diploma may not be substantively important in explaining the black-white educational attainment gap. The reason is that, as Becker and Mulligan (1997) demonstrate, rates of time preferences are endogenous. Seen from this perspective, the high rates of time preference of black children, who tend to grow up in lower-income families than white children, are likely to stem from lower investments in their skill development during the early childhood years (Heckman 2008, 2011).

Recent research also sheds light on the role parental investments play in explaining gender gaps in socioemotional skills, rates of time preference, and high school graduation rates. Bertrand and Pan (2013) document that boys have lower levels of socioemotional skills than girls as fifth graders. Most notably, their teachers are more likely to report that boys exhibit "externalizing problems," reflected in fighting, getting angry, or disturbing classroom activities. Boys are also much more likely than girls to be suspended from school as eighth graders. While Bertrand and Pan's data do not allow 
them to examine whether children who exhibit externalizing problems have a lower probability of graduating from high school, other studies document that this is the case (Castillo et al., 2011).

Bertrand and Pan (2013) show that gender differences in externalizing problems are much greater among children raised in single-parent families than those in two-parent families. They document that boys in one-parent families (almost all of which are female-headed) receive less and lower-quality parental supports than girls raised in single-parent families. They also find that boys’ noncognitive development (including the incidence of externalizing problems) is much more sensitive to the level and quality of parental inputs than girls’. Bertrand and Pan (2013) also shed some light on the reasons gender gaps in high school graduation rates are larger among black youth, and to a lesser extent among Hispanics, than among whites. In 2009, only 37 percent of blacks under age eighteen lived in families with both of their parents. The comparable figures for Hispanic and white children are 67 and 75 percent, respectively (Kreider and Ellis, 2011). Of course, this pattern raises the difficult and important question of why only a minority of black children in the U.S. grow up in families with both of their parents.

\subsection{The Nonmonetary Cost of Completing Another Year of Schooling}

Measures of cognitive skills and behavior measured as early as age five predict the probability that children will graduate from high school. ${ }^{58}$ This pattern indicates that differences in children’s early experiences may account for patterns in high school graduation rates by influencing the nonmonetary costs students face in completing high school graduation requirements. Several studies show that in utero shocks affect children's intellectual development with consequences for educational attainments. For example, Almond, Edlund, and Palme (2009) show that in utero exposure to radiation from the Chernobyl disaster affected the cognitive skills of Swedish children

\footnotetext{
58 See Appendix Table 3.A9 in the online appendix to Duncan and Magnuson (2011). For other evidence on the same topic, see McLeod and Kaiser (2004).
} 
and the probability that they graduated from high school, with the effects concentrated on children whose parents had relatively low levels of educational attainments. Almond and Currie (2011) summarize other evidence on the effects of in utero shocks on children's development, pointing out that the effects are greatest for children from relatively low-income families, perhaps because they lack the resources to make compensatory investments in children whose skill development lags.

Several studies show that the cognitive and non-cognitive skills of black and Hispanic children measured at the beginning of kindergarten are lower, on average, than those of white children. The skill gaps stem to a considerable extent from differences in parental investments during early childhood (Cunha and Heckman, 2008; Cunha, Heckman and Schennach, 2010; Cunha et al., 2006; Fryer and Levitt, 2004). The evidence on whether black-white gaps in reading and math skills change during the elementary school years and the role of school quality in explaining trends is ageand grade-dependent. Fryer and Levitt (2006) report that black-white skill gaps widen between kindergarten and Grade 3. However, differences in school quality cannot account for the growth. Hanushek and Rivkin (2009) and Clotfelter, Ladd, and Vigdor (2009) report that black-white gaps widen between Grades 3 and 8 among children who start school with relatively high achievement. Hanushek and Rivkin (2009) report that differences in teacher quality and peer group composition account for a large part of the increase. ${ }^{59}$

Studies examining the effects of court-ordered desegregation also indicate the importance of school quality. Using different data sets, Guryan (2004) and Johnson (2011) show that court-ordered school segregation plans implemented during the 1960s, 1970s, and 1980s that sent students of color to better public schools increased their high school graduation rates. Lutz (2011) shows that the termination of court-mandated desegregation orders in school districts outside of the South resulted in

\footnotetext{
${ }^{59}$ Bond and Lang (in press) show that trends in black-white skills gaps can be quite sensitive to the metric used in measuring children's skills.
} 
a marked increase in the school dropout rate of black youth. Deming et al. (2011) show that for students living in neighborhoods served by low-quality public schools in Charlotte-Mecklenburg, North Carolina (the majority of whom were black or Hispanic), the opportunity to attend a better middle school or high school increased the probability of high school graduation by 9 percentage points. ${ }^{60}$ These studies provide convincing evidence that low school quality and the consequent high cost of obtaining the knowledge and skills needed to complete core courses and pass exit examinations are important factors contributing to the relatively low high school graduation rate of black and Hispanic students. Indeed, this same evidence helps to explain the concentration of dropouts among students attending a minority of the nation’s high schools.

A more difficult question to answer is whether increases in the cost of obtaining a high school diploma explain the stagnation of the high school graduation rate during a period in which the labor market payoff to high school graduation increased. The evidence seems to support this proposition. In essence, the line of reasoning has two parts: first, requirements for earning a high school diploma have increased, and second, the increase in requirements had a negative impact on the graduation rate of vulnerable groups. We consider the two parts in turn.

In response to concerns that the weak skills of the U.S. labor force contributed to the slow rate of economic growth in the decades after 1973, states took a number of actions to improve the skills of students graduating from public high schools. Among the first of such actions was the introduction by nineteen states of minimum competency tests for graduation. These early steps were followed by increased course requirements and more challenging exit examinations, all of which increased the cost of obtaining a high school diploma for students with weak academic preparation.

\footnotetext{
${ }^{60}$ Deming (2011) shows that the opportunity to attend a better high school in Charlotte-Mecklenburg also reduced the number of crimes that high-risk youth committed over the next seven years.
} 
The watershed document on the quality of the nation's public school system was A Nation at Risk, published in 1983. The report concluded that, "the educational foundations of our society are presently being eroded by a rising tide of mediocrity that threats our very future as a Nation and a people” (p. 5). The authors recommended that a condition for receipt of a high school diploma should be that students complete four years of English, and three years of mathematics, science, and social studies, and many states complied. By the early 1990s, attempts to improve public education had morphed into the standards-based educational reform agenda, often called test-based accountability. Although details vary greatly from state to state, standards-based educational reforms typically include content standards that specify what students should know and be able to do, performance standards that specify the levels of performance students should satisfy, assessments that measure the extent to which students meet performance standards, and incentives for students and educators to meet the standards. One consequence of test-based accountability is that in the 2011-2012 school year, 70 percent of all public high school students had to pass at least one exit examination to obtain a high school diploma (McIntosh, 2012).

The second part of the line of reasoning is that increases in high school graduation requirements reduced the high school graduation rates of vulnerable groups. This has proved difficult to demonstrate convincingly for four reasons. First, the exit examinations that states introduced vary enormously in difficulty. Consequently, it is likely that the impact of their introduction varies. Second, states vary substantially in the extent to which they bolstered resources to improve instruction and support for students who either failed a core course or an exit examination or whose low prior achievement put them at risk of failure. Third, in some states, including Massachusetts, local districts specify the courses that must be passed; many have raised the requirements. Consequently, state requirements do not accurately reflect graduation requirements in individual 
school districts. Fourth, the accuracy of available information on high school graduation rates varies among states and among data sources for reasons described in Section 2. Given this variation among states, it is not surprising that the evidence on impacts is not completely consistent, even among studies with plausible identification strategies.

Although not without exceptions, the evidence indicates generally that increased graduation requirements have reduced high school graduation rates among low-achieving students (including those with learning disabilities), students of color, and urban low-income students. For example, Jacob (2001) and Bishop et al. (2001) find that increased requirements reduced high school graduation rates of low-achieving students by 6 to 7 percent. Dee and Jacob (2007) also report negative, albeit considerably smaller, impacts of minimum competency tests on the high school graduation rates of particular disadvantaged groups.

The pattern is somewhat stronger, although again with some exceptions, on the impacts of more difficult standards-based exit examinations that states have adopted during the last two decades. Reardon and Kurlaender (2009) and Reardon et al. (2010) use data on three cohorts of students from four large California school districts to examine these impacts and find that the introduction of exit examinations reduced high school graduation rates by approximately 4 percentage points, with effects concentrated among low-achieving students, minority students, and English language learners. Warren, Jenkins, and Kulick (2006) and Dee and Jacob (2007) report that exit exam requirements reduced high school graduation rates by about 2 percentage points, with larger effects in states with more difficult examinations, and with effects concentrated among black students and among students in districts with large percentages of students of color.

The quality of the evidence is especially weak on the impact that increases in course completion requirements have on high school graduation rates. One reason is that in at least some 
states, school districts have subverted the intention of the policy by introducing relatively

undemanding courses. Nonetheless, Lillard and DeCicca (2001) estimate that a one standard deviation increase in course graduation requirements increased the population of school dropouts in 1990 by 3 to 7 percent. $^{61}$

Given the focus of this paper, I describe the evidence bearing on how increases in graduation requirements have affected high school graduation rates. However, it is important to keep in mind that states increased high graduation requirements and introduced other aspects of standards-based educational reforms in order to improve the quality of education students receive and to make a high school diploma a stronger signal of skill mastery. An assessment of the benefits and costs of these controversial educational reforms goes beyond the scope of this paper, and in any case would need to be state-specific. Nonetheless, it is important to remember that advocates of standards-based educational reforms can point to accomplishments. For example, comparisons of the transcripts of 1990 and 2009 high school graduates carried out under the auspices of the National Assessment of Educational Progress found that larger percentages of 2009 graduates from all major racial/ethnic groups completed a more rigorous curriculum than did comparable 1990 graduates, and, on average, 2009 graduates completed about 420 more hours of course work than did 1990 graduates (Nord et al., 2011). Moreover, many advocates of better education for disadvantaged children embrace standardsbased reforms, arguing that they are critical to setting high expectations for the achievement of all children. They point to schools serving high concentrations of disadvantaged students that have responded productively to the pressure of test-based accountability. ${ }^{62}$ Thus, it is in the context of a

\footnotetext{
${ }^{61}$ The authors use a difference-in-differences methodology to obtain their estimates. They recognize that a threat to the validity of their results is that states that increased course requirements also took other steps such as the introduction of exit examinations that may have reduced high school graduation rates.

${ }^{62}$ See Balfanz et al. (2010), and Ferguson et al. (2010) for evidence on high poverty schools that have improved their performance under test-based accountability systems.
} 
reform approach that has altered U.S. public education in many respects that I summarize the evidence on its impact on high school graduation rates.

In summary, my interpretation of the evidence is that increases in high school graduation requirements during the last quarter of the twentieth century increased the nonmonetary cost of earning a diploma for students entering high school with weak skills. By so doing, they counteracted the increased financial payoff to a diploma and contributed to the stagnation in graduation rates over the last decades of the twentieth century. Of course, this raises the question of why high school graduation rates increased during the first decade of the twenty-first century, a period in which high school graduation requirements were not reduced, and in some states were increased. ${ }^{63}$ To my knowledge, there is no compelling explanation for this increase during the 2000s or for the especially large increases in the graduation rates of black and Hispanic students. However, evidence from the NAEP provides a clue. Figure 6 displays trends by racial/ethnic group between 1978 and 2008 in the twenty-fifth percentile on mathematics and reading scores for thirteen-year-olds from the long-term NAEP. I focus on the twenty-fifth percentile scores because students at the low end of the score distributions are at greatest risk of not graduating from high school. (The trends in the tenth percentile are very similar.)

The twenty-fifth percentile mathematics score for black thirteen-year-olds was virtually unchanged between 1986 and 1999. In contrast, between 1999 and 2008, it increased by 11 points, approximately 0.35 standard deviations. The pattern for Hispanics is similar, with the twenty-fifth percentile mathematics score remaining almost unchanged between 1986 and 1996, and then increasing by 12 points (.38 standard deviations) between 1996 and 2008. The twenty-fifth percentile

\footnotetext{
${ }^{63}$ For example, beginning with the graduation class of 2011, high school students in New York must pass state Regents examinations in five subjects to obtain a high school diploma. Earlier cohorts were required to pass fewer examinations and if they did not do so, could receive a "local diploma."
} 
mathematics score for thirteen-year-old white students increased by 0.29 standard deviations over the same period. The trends in eighth grade reading scores are somewhat different, but equally striking. Between 1988 and 1994, the twenty-fifth percentile reading score of black eighth graders and Hispanic eighth graders fell by 0.25 and 0.13 standard deviations, respectively. Between 1996 and 2008, the corresponding scores increased by 0.36 and 0.11 standard deviations.

Thus, the evidence from the NAEP indicates an improvement over the last ten to fifteen years in the reading and mathematics skills among entering freshman at the bottom of the skills distribution. This may have translated into lower nonmonetary costs of completing high school graduation requirements. Moreover, the impact may have been particularly great for black and Hispanic students, given that larger shares enter ninth grade with weak mathematics skills than do white students (Ho, 2008).

[Figure 6 about here]

It is not clear why the mathematics skills of thirteen-year-olds at the bottom of the skills distribution have risen. It could be the result of improved schooling in Grades K-8. However, it could also stem from improvements in the out-of-school circumstances of American children most at risk of academic failure. For example, between 1980 and 2000, the fraction of American four-year-olds enrolled in classroom-based preschool programs increased from one-half to two-thirds (Barnett and Yarosz, 2007). This trend could have resulted in more children acquiring the cognitive and socioemotional skills needed for success in high school.

There are other trends in the circumstances of children at risk of academic failure that could have contributed to the increase in the high school graduation rate. For example, the birth rate among fifteen- to seventeen-year-old girls declined by 44 percent between 1990 and 2008, and by 60 percent 
among black teens (Ventura et al., 2012). Because children born to teenage mothers are prone to develop externalizing problems that inhibit academic success, this trend could have contributed to both the increases in the mathematics skills of thirteen-year-olds and to an increase in the high school graduation rate. Moreover, the decline in the teenage birth rate could have reduced the number of girls who left school to care for children and thus resulted in higher graduation rates. Yet another salutary trend is a 47 percent decline between 1994 and 2009 in the arrest rate of teenagers for violence-related offenses (OJJDP Statistical Briefing Book, 2011). One of several reasons this could have contributed to an increase in the high school graduation rate is that involvement with the criminal justice system typically results in a marked increase in absences from school (Kirk and Sampson, 2011).

In summary, there are many hypotheses for why the high school graduation rate of twenty- to twenty-four-year-olds in 2010 is higher than it was in 2000, and why the increase in the graduation rate was particularly large for blacks and Hispanics. However, to date, there is no compelling evidence to explain this encouraging recent trend.

\subsection{The Availability and Value of Alternative High School Completion Credentials}

Economic models posit that students' responses to increases in the cost of acquiring a high school diploma will depend on the attractiveness and cost of alternatives. The most common alternative to a diploma is the GED. Between 1970 and 1995, the percentage of new high school completion credentials awarded through GED certification increased from 2 percent to 17 percent. ${ }^{64}$ In 2002, after the GED Testing Service introduced a more difficult set of GED tests, the percentage dropped to 10 percent. Since 2004, it has held steady at about 12 percent. Factors contributing to the

\footnotetext{
${ }^{64}$ In 2001, the percentage was 18.5 percent. However, this figure is an anomaly reflecting the especially large number of individuals in the U.S. $(648,022)$ who took and passed the GED examinations in the last year before the GED Testing Service introduced more difficult GED exams. In the year 2000, 486,977 individuals in the U.S. passed the GED exams.
} 
increasing role of the GED during the last three decades of the twentieth century include reductions in the minimum age for taking the exams, investments by states in GED preparation programs, the creation and expansion of programs to prepare incarcerated individuals to take the GED examinations, and increased requirements for receipt of a conventional high school diploma.

The critical question is whether the availability of the GED leads some teenagers to drop out of school who, in the absence of the GED, would have graduated from high school. Heckman et al. (2012) use evidence from three natural experiments to answer this question. The first was a 1997 mandate by the GED Testing Service that all states adopt minimum passing scores on the five GED tests; the new scores were higher than those in place in thirty-one states. Using a difference-indifferences estimation strategy, the authors find that increases in GED minimum score requirements reduced the dropout rate among black and Hispanic twelfth graders in affected states by 4.4 and 7 percentage points, respectively. The comparable figure for white twelfth graders was 1.4 percentage points. The second natural experiment was the introduction of the "GED Option Program" into high schools in Oregon in 2001. This program targets students at risk of dropping out of high school and helps them to obtain GED certification while enrolled in high school. Heckman and colleagues show that the introduction of the program reduced high school graduation rates by 4 percent. The third natural experiment was the 1973 decision of the California legislature to make the GED available to civilians in 1974. Again using a difference-in differences estimation strategy, Heckman and his coauthors find that the GED option lowered the high school graduation rate by 3.6 percentage points for males and by 2.6 percentage points for females.

The reason the magnitude of the displacement effect matters is that, on average, the GED is not a wise choice for students who could obtain a conventional high school diploma; GED recipients do not fare as well in the labor market and in postsecondary education as conventional high school 
graduates (Cameron and Heckman, 1993; Heckman and LaFontaine, 2006; Murnane, Willett, and Tyler, 2000). Heckman, Humphries, and Mader (2011) point out that the poor subsequent track record of GED recipients lies in poorer socioemotional skills such as motivation and persistence, skills that high school graduates demonstrate by completing course requirements. In this regard, Heckman and Rubinstein (2001) refer to the GED as a "mixed signal," indicating to potential employers that the recipient has mastered basic cognitive skills but is unlikely to have the socioemotional skills that result in the regular attendance and punctuality that employers value.

Although there is no question that, on average, GED recipients do not fare as well in the labor market and in postsecondary education as conventional high school graduates, a different question is whether the credential provides value to school dropouts who conclude that they cannot return to high school and obtain a conventional diploma. The question matters because if there are benefits to dropouts from obtaining the GED credential, they need to be weighed against displacement effects in evaluating public policies regarding the GED. Heckman and LaFontaine (2006) report that, when estimated in models that control for cognitive skills and that assume homogeneous effects of educational credentials, GED recipients do not earn more than uncredentialed dropouts. Applying a regression discontinuity identification strategy that accounts for the multiple times candidates may take the GED tests, Jepsen, Mueser, and Troske (2010) reach the same conclusion.

In contrast, Tyler, Murnane, and Willett (2000) find that the GED increases the earnings of young low-skilled white dropouts by 10 percent to 19 percent. Their study uses Social Security earnings records merged with information on GED test scores and an identification strategy that takes advantage of differences in minimum GED passing scores across states. Their estimates pertain to low-skilled dropouts, defined as those with cognitive skills just sufficient to obtain the GED 
credential in low standard states but not in high standard states. ${ }^{65}$ Using data from High School and Beyond survey, Murnane, Willett, and Tyler (2000) replicate the Cameron and Heckman (1993) finding of no effect of the GED on the earnings of recipients, when estimated in a model that controls for cognitive skills and assumes a homogenous effect of the GED. They also replicate the finding of a positive effect on the earnings of dropouts with low cognitive skills, when estimated in a model that allows for heterogeneous effects by initial skill level.

My explanation of the economic benefits of the GED credential to individuals who drop out of school at age sixteen with weak cognitive skills and poor attitudes is informed by discussions with teachers of GED test preparation programs. The instructors report that many such individuals enter their programs after several years of bad labor market experiences. The participants feel they have matured and would make better workers than they were at age sixteen, but they find it difficult to convince employers to give them a chance. They hope that the GED credential will provide a favorable signal. Tyler, Murnane, and Willett (2000) report that the credential does this for dropouts with weak skills, enabling them to increase their annual earnings from an average of $\$ 9,628$ to $\$ 11,101$ five years after receipt of the GED. The $\$ 11,101$ earnings figure is nevertheless still well below the poverty level for a family of three in 1995. This is consistent with the Heckman and Rubinstein view of the GED as a "mixed signal," one that replaced the unequivocally poor signal that the dropouts previously carried.

Teenagers with stronger cognitive skills leave high school for myriad reasons—-for example, they dislike school, they experience problems at home, or they are expecting a child. The modal

\footnotetext{
65 The results reported by Jepsen, Mueser, and Troske (2010) conflict with those reported by Tyler, Murnane, and Willett (2000). Both groups examine the impact of the GED on the subsequent earnings of individuals whose scores on the GED examinations are just on the margin for passing. Since one of the natural experiments that Tyler and his colleagues study takes into account the fact that some individuals retake the GED examinations, it seems unlikely that the difference in results stems from differences in the treatment of the retaking option. One possible explanation is that labor market conditions in Missouri, the site of the study by Jepsen and his colleagues, differ from those in the states included in the analyses reported by Tyler et al.
} 
reason they take the GED tests is to gain access to funding for postsecondary education or training. Indeed, 43 percent of GED recipients enter college or training programs within six years of obtaining the credential. However, only half of these return for the second semester, and very few complete a degree program (Patterson et al., 2010). This explains why the GED credential provides little or no economic benefit to these recipients.

In summary, the existing evidence indicates that the availability of the GED credential does lead some teenagers to drop out of school who otherwise would have persisted to graduation. As a result, its increasing availability to teenagers between 1970 and 2000 contributed to the stagnation of the high school graduation rate during a period when the economic payoff to graduation grew and the requirements for earning a high school diploma also increased. It is possible that the introduction of more difficult GED examinations in 2002, which resulted in a temporary decline in the number of 1618 year-olds obtaining the credential, contributed to the increase in the high school graduation rate over the decade 2000-2010. However, I know of no causal evidence that this is the case. ${ }^{66}$

\section{Increasing High School Graduation Rates: The Causal Evidence}

In this section I describe policy interventions that, based on impact evaluations with plausible identification strategies, either increase the high school graduation rate or reduce the dropout rate of students with particular characteristics. To keep the scope of this section manageable, I do not consider interventions for which evaluations showed impacts on student test scores, but not on graduation or dropout rates. This excludes most interventions targeted at younger children. I organize the description by the age of children for whom the interventions are relevant.

\subsection{Early Childhood Interventions}

\footnotetext{
66 The trends over the last decade in the number of 16-18 year-olds who passed the GED examinations are puzzling. Between 2003 and 2008, the number increased steadily from 137,619 to 160, 143. Since 2008, the number has declined steadily, falling to 116,309 in 2011.
} 
As Nelson and Sheridan (2011) explain, essential properties of most of the brain's architecture are established very early in life by genes, experiences, and their interactions. For this reason, policy interventions aimed at enriching the early experiences of economically disadvantaged children may be particularly effective in helping them to develop the cognitive and socioemotional skills necessary to succeed in school and in later life. Evidence from small model preschool education programs, including Perry Preschool and the Abecederian programs, indicate positive impacts on high school graduation rates for females ${ }^{67}$ However, the question remains whether preschool education programs implemented at large scale would also have long-term benefits for economically disadvantaged children, including an increase in the probability of high school graduation.

Evidence from the Child-Parent Center Education (CPC) program is encouraging. Since 1967, this program has provided intensive education and family-support services to children aged three to nine from low-income, primarily black families in Chicago. An evaluation of the CPC program finds that the on-time high school graduation rate for children who participated in the CPC program during their preschool and primary school years (44.3 percent) is 7.7 percentage points higher than that of a matched control group of children who did not participate in the CPC program. The difference is larger, at 17.3 percentage points, for children who participated in the CPC program during both their preschool and primary school years (Reynolds et al., 2011). The CPC program serves many more children than the small model programs described above. For that reason, the evidence on long-term outcomes, including high school graduation rates, is encouraging. However, the program served children in only one city, Chicago.

\footnotetext{
${ }^{67}$ The impact evaluations of the Perry Preschool and the Abecedarian program did not find statistically significant, positive impacts on educational attainments for boys. There were other long-term benefits for boys, however, especially in crime reduction. See Heckman, Moon, Pinto, Savelyev, and Yavitz (2010) for a summary of benefits from the Perry Preschool program.
} 
The largest publically funded program in the United States designed to improve the health and education of very young disadvantaged children is Head Start. Introduced in 1965 as part of the Great Society initiative, and currently serving approximately 900,000 disadvantaged children, Head Start offers a variety of services, including preschool education and health and nutrition services. Using a creative regression-discontinuity-based identification strategy and data from the U.S. census and from the National Education Longitudinal Study (NELS88), Ludwig and Miller (2007) find that the offer of Head Start to children living in the nation's three hundred poorest counties during the first years of the program increased the probability of high school graduation by approximately 3 percentage points. Using data from the Panel Study of Income Dynamics pertaining to children born in the 1960s and an estimation strategy that compares outcomes among siblings, Garces, Thomas, and Currie (2002) find that participation in Head Start increases the probability of high school graduation by 20 percentage points for white children, but has no impact for black children. A possible explanation for the differential effects by race is that black children were unable to sustain the benefits from Head Start because they attended very low quality elementary and high schools. ${ }^{68}$

Using data from the Children of the National Longitudinal Survey pertaining to children born during the 1980s and the same identification strategy based on comparing outcomes for siblings, Deming (2009) finds that participation in Head Start increases the probability of high school graduation by 11 percentage points for males and by 13 percentage points for children of mothers with low cognitive skills. ${ }^{69}$ A recent study by Havnes and Mogstad (2011) that focused on a very different population finds results similar to Deming's. These authors report that participating in subsidized child care in formal settings in Norway during the preschool years reduces the probability

\footnotetext{
${ }^{68}$ Differences in the quality of the schools attended by children of different races would also explain Cascio's (2009) finding that the impact of the introduction of public kindergarten in states (primarily in the South) increased the high school graduation rate of white children, but not that of black children.

${ }^{69}$ These estimates come from models in which GED recipients are not counted as high school graduates (see Deming 2009, pp. 126-27).
} 
of dropping out of high school by 7 percentage points for children whose mothers had not graduated from high school.

In summary, a significant number of studies provide evidence that public investment in improving education, health, and nutrition during the preschool years is a promising strategy for increasing the probability that economically disadvantaged children graduate from high school. ${ }^{70}$ However, important questions remain about the intensity and quality of programs needed to improve long-term outcomes for disadvantaged children. For example, a recent random assignment evaluation of Head Start finds that cognitive and socioemotional outcomes at the end of first grade are not consistently stronger for children who have participated in Head Start than for those who have not (U.S Department of Health and Human Services, 2010). Two plausible explanations for the differing results of this and earlier studies are, first, that the quality of alternatives to Head Start may have improved so that the difference between the early childhood experiences of Head Start participants and nonparticipants today is less than it was several decades ago. Second, it is possible that the average quality and intensity of Head Start programs are much lower than those of the CPC program in Chicago or some other public pre-school programs that have shown promising results. ${ }^{71}$

\subsection{Elementary Schools}

In the mid-1980s, the Tennessee state legislature appropriated funding for a randomized experiment to evaluate the causal impact of class size reduction on the reading and mathematics achievement of children in the primary grades. More than 11,000 students and 1,300 teachers in 79 public schools participated in the Student/Teacher Achievement Ratio (STAR) experiment. In each participating school, children entering kindergarten in the fall of 1985 were assigned randomly to a

\footnotetext{
${ }^{70}$ For a recent review of evidence on the impacts of early childhood interventions on long-term outcomes including the probability of high school graduation, see Almond and Currie (2011). For a review of the quite discouraging evidence on interventions designed to improve parenting practices, see Furstenberg (2011).

${ }^{71}$ See Gormley, Phillips, and Gayer (2008) and Weiland and Yoshikawa (in press) for promising recent evaluations of a public pre-school program.
} 
small class with thirteen to seventeen children or to a regular size class with twenty-two to twentyfive students. ${ }^{72}$ Teachers in each school were also randomly assigned to classrooms. The research design called for students to remain in their originally designated class type through third grade.

Researchers have conducted follow-up studies examining the impact of the intervention on participants' subsequent educational attainments and, most recently, on adult labor market outcomes. Particularly striking are the results of the analysis by Chetty and his colleagues (2011), who examine the impact of kindergarten class size and class quality (measured by classmates' end-of-year test scores) on long-term outcomes measured from administrative data. The authors report that children assigned to a small kindergarten class and those assigned to a high-quality class are more likely to attend college than those assigned to a larger or lower-quality class, and they have better adult outcomes in general.

Although Chetty et al. (2011) did not examine impacts of class size on high school graduation rates, it seems likely that one of the ways that the program led to improved adult outcomes is by increasing graduation rates. Diane Whitmore Schanzenbach, one of the authors of the Chetty et al. (2011) study, provided me with estimates of the intervention on high school graduation rates. She finds that assignment to a small class for the first year in school increases the probability of high school graduation by 9 percentage points (from a base of a 0.59) for black male children, and by 7 points (from a base of 0.60) for male children from low-income families (a heavily overlapping group) ${ }^{73}$ These results are particularly striking given the racial and gender gaps in high school graduation rates.

\footnotetext{
${ }^{72}$ In fact, there were three treatments in the STAR experiment: a small class, a regular-sized class with one teacher, and a regular-sized class with one teacher and a full-time aide. However, given that there are no differences in average outcomes between students assigned to the second and third treatments, almost all analysts have combined students in these two treatment arms.

${ }^{73}$ The $p$ value associated with this point estimate is 0.091 . The corresponding point estimate of the impact of assignment to a small class on the high school graduation rate of male children from low-income families is an increase of 7 percentage points $(p=0.043)$. The corresponding estimates for female black children and for females from low-income
} 
In considering the substantive lessons from Chetty et al. (2011), it is important to keep two patterns in mind. First, many of the high-quality kindergarten classes in the STAR experiment contained the normal number of students (approximately twenty-four). Second, the magnitude of the effect of class quality on adult outcomes is approximately the same size among children enrolled in regular size kindergarten classes as among those enrolled in small classes. For this reason, I believe that the critical lesson from the STAR experiment is that providing children, particularly males from minority groups or low-income families, with a strong start in school is a powerful lever for increasing their high school graduation rate and life chances. A second lesson implicit in the findings of Chetty et al. (2011), although not emphasized, is that different combinations of inputs (for example, class size, peer group composition, and teacher quality) will produce the same set of student outcomes. Figuring out the most efficient way to provide all children, especially those from high-risk groups, with a strong start in school is a critical policy challenge. ${ }^{74}$

In another study that also involves linking school records with administrative data on adult outcomes, Chetty, Friedman and Rockoff (2011) examine the impact of teacher quality, as measured by their "value-added" in enhancing the reading and math scores of children in Grades 4-8, on students' long-term outcomes. They find that students assigned to high value-added teachers in any of these grades are more likely to attend college and to have higher subsequent earnings than children assigned to lower value-added teachers. The authors lack the data to examine impacts of teacher value-added on student high school graduation rates. However, given that relatively few high school dropouts enroll in college, it seems likely that the college-going results stem at least in part from positive effects of good elementary school teaching on the probability of high school graduation.

\footnotetext{
families are not statistically different from zero. Finn, Gerber, and Boyd-Zaharias (2005) also report positive impacts of the STAR small class treatment on high school graduation rates.

${ }^{74}$ Jepsen and Rivkin (2009) present evidence from California indicating that going to scale with across-the-board class size reductions is unlikely to be the most efficient way to improve the quality of kindergarten and primary school education provided to disadvantaged children.
} 
Thus, these results indicate that providing students with effective elementary and middle school teachers may be an important strategy for increasing high school graduation rates. ${ }^{75}$

\subsection{Middle Schools}

Two studies explore whether the grade configuration of schools serving children in the years before entry into high school affects the probability of high school graduation. Three grade configurations are dominant: K-8 schools, junior high schools serving students in Grades 7 and 8 and sometimes 9, and middle schools serving students in Grades 6-8. Using information from the CCD, Bedard and Do (2005) find that moving from a system in which students change schools at the end of Grade 6 to a system in which they change schools at the end of Grade 5 reduces the on-time high school graduation rate by 1 percent to 3 percent. They argue that this reflects a detrimental effect on students who are less able academically. ${ }^{76}$

Schwerdt and West (in press) use administrative data from the Florida public schools to examine the consequences for students of alternative grade configurations. They find that students who attend an elementary school ending in Grade 5, and consequently change schools in Grade 6 and again after Grade 8, have a 1.4 percentage point (14.5 percent) higher dropout rate between Grades 9 and 10 than students who attend a K-8 elementary school. ${ }^{77}$ The authors hypothesize that moving from a school in which a particular cohort of students is the oldest to a school in which the cohort is the youngest is a difficult experience, particularly for low-achieving students, and doing so increases

\footnotetext{
${ }^{75}$ The authors are very careful to point out that their study provides no guidance about efficient strategies to provide more of the nation's children with effective teachers.

${ }^{76}$ Bedard and Do mention, but do not test, several possible mechanisms to explain why an additional year in elementary school is beneficial to low-achieving students. One mechanism they do not mention, but subsequent research supports, is that elementary school teachers teach reading skills while middle or junior high school teachers typically do not. Many children enter fifth grade without the reading skills to make sense of social studies and science texts. Thus, spending an additional year in a classroom in which teachers devote attention to reading instruction may help low-achieving students to acquire skills critical to their subsequent academic success. For a discussion of this potential mechanism, see Goldman (2012).

${ }^{77}$ Schwerdt and West (in press) also report that students who change schools at the end of Grade 6 and again at the end of Grade 8 have a slightly higher dropout rate than students who attend K-8 schools. But the difference is not statistically significant.
} 
the probability that they will leave school prior to high school graduation. A complementary interpretation is that changing schools, per se, has a negative impact on children's academic progress. Consequently, it makes sense to minimize the number of times students have this experience.

\subsection{High Schools}

Deming and colleagues (2011) examine the impact of high school quality on the probability of high school graduation for teenagers in Charlotte-Mecklenburg, North Carolina. Their identification strategy takes advantage of lotteries that enable winners to enroll in a public high school they choose that is different from the one serving their local neighborhood. The majority of students who participated in the lotteries were black and were eligible for free- or reduced-price lunch. Deming and his colleagues find that enrolling in the public high school of their choice increases the probability of high school graduation by 5.5 percentage points. For students living in neighborhoods served by lowquality high schools, enrolling in their preferred high school creates a 14 percentage point increase in the probability of graduation. One reason for these better outcomes is that students who enroll in their preferred high school are much more likely to be “on track” in completing college-preparatory science and mathematics classes needed for graduation. The authors also report that the impact of high school quality on the probability of graduation is much larger for female than male students.

The Talent Development High School Model is a whole school reform approach that focuses on changing the experiences of students entering high school. Targeted at high schools serving high percentages of low-achieving minority students, Talent Development places all ninth graders in learning communities of 100 to 125 students taught by the same four or five teachers. The schedule allows ninth graders to take double doses of mathematics and English aimed at providing the skills needed to do high school level work. Students also take a "Freshman Seminar" designed to help them develop study skills and to cope with personal adjustment issues. In this reform model, students then 
move to career academies, which provide both learning communities and curriculum based on career themes.

An impact evaluation conducted by the research firm MDRC using an interrupted time series approach finds that Talent Development increases the rate of on-time graduation by 8 percentage points in the two earliest implementing schools, which were the only schools in which students were tracked long enough to observe high school graduation rates (Kemple, Herlihy, and Smith, 2005). However, the MDRC researchers caution that the early-adopting schools received strong support from the program developers and also benefited from stable leadership, and that their results may not be representative of those of other Talent Development schools in the district (although, like the early-starting schools, the later-starting schools implementing this reform produced positive effects on promotion rates and credits earned). ${ }^{78}$

A high school reform initiative carried out over the last decade in New York City also shows that high school quality makes a difference in the probability that economically disadvantaged urban students graduate. Starting in 2002, New York City closed more than twenty large low-performing high schools and opened more than two-hundred small schools in their place. The city stressed innovative approaches to educating low-income urban students. The district invited stakeholders, including groups of teachers, school reform organizations, and entrepreneurs from other sectors to join forces in submitting proposals for new schools. Plans for involvement of community partners in students' education were a required part of each proposal. Winners of the design competition received start-up funds and support for leadership development and the recruitment of strong teachers. In

\footnotetext{
${ }^{78}$ Evaluations showing positive impacts on outcomes in schools in which founders provided strong support are often not replicated when the intervention is tried in other sites. For example, this pattern is present in the MDRC evaluations of "Project Grad" and "First Things First," two whole school reform interventions targeted at low-performing high schools. See Snipes et al. (2006), and Quint et al. (2005).
} 
addition, each school was paired with at least one intermediary organization skilled in launching new schools.

The New York City initiative demonstrates that new approaches to secondary education for low-income students are possible to implement at considerable scale, even in a large urban district widely viewed as excessively bureaucratic and resistant to change. Even more important, the results of an impact evaluation in which the identification strategy was based on the results of lotteries that determined access to the 105 oversubscribed small schools with no academic admission requirements, are encouraging. The evaluation showed that enrolling in one of the 105 oversubscribed small schools of choice increased the four-year high school graduation rate of students, the majority of whom entered ninth grade reading well below grade level, from 59 to 68 percent. $^{79}$

The evidence on high school reforms that are effective in increasing graduation rates for economically disadvantaged students is much too thin to provide anything like a set of blueprints for improving secondary school education. However, it does suggest several lessons for reform efforts. The first is the importance of providing a great deal of support and guidance to incoming ninth graders, many of whom are anxious about their ability to function in a new school in which they are the youngest students. Both the Schwerdt and West (in press) and the Talent Development evaluation support this suggestion. Second, given the diverse needs and interests of teenagers, it makes sense to create low-cost opportunities, such as the New York City small school design competition, for groups of educators and partners to develop and implement new models for educating academically struggling students. Third, there is promise in developing small schools that provide a focused

\footnotetext{
79 For a description of the methodology and results of the MDRC evaluation, see Bloom, Thompson, and Unterman (2010) and Bloom and Unterman (2012). The latter report documents that the percentage of the treatment group that graduated from high school within five years was 7 percentage points higher than the five-year graduation rate of the control group. This is important because evaluations of other high school interventions have shown that treatment impacts on high school graduation rates dissipated over time as the control group caught up with the treatment group. See, for example, Rodríguez-Planas (2012).
} 
program of instruction that all students follow. This may help to develop the positive achievement culture that Akerlof and Kranton (2000, 2002) see as critical to effective schooling. Fourth, creating learning opportunities outside of school, such as internships in professional workplaces, may enable students from low-income families to acquire critical cognitive and socioemotional skills and to recognize the benefits of academic success. Evidence supporting this lesson comes from both the evaluation of the New York City small-schools-of-choice initiative and evidence from the MDRC evaluation of career academies. ${ }^{80}$

A final lesson from the evidence on effective high school reforms is that increasing the graduation rate of teenagers who enter ninth grade with weak cognitive and socioemotional skills is extraordinarily difficult work. The evidence from the successful high school initiatives demonstrates this lesson. While these initiatives increased graduation rates markedly, they all left a great many students without a high school diploma. For example, more than 50 percent of the students in the Talent Development high schools in Philadelphia failed to graduate on time. Among lottery winners in the Charlotte-Mecklenburg schools, one quarter failed to graduate. Among students who enrolled in a New York City small school of choice, one-quarter failed to graduate in five years. These sobering figures underscore the importance of interventions aimed at providing young children from low-income families with a strong start so that they enter ninth grade with the foundational skills needed to succeed in high school.

\subsection{Why Is the Evidence So Sparse?}

\footnotetext{
${ }^{80}$ Ongoing research on the New York City small schools of choice should shed light on the extent to which learning opportunities outside of school provided by community partners contributed to the effectiveness of these schools. Page (2012) documents that providing greater exposure to the world of work contributed to the success of career academies in enhancing long-run labor market earnings for participating students. I did not describe the career academies study in this paper because students who won a lottery to enroll in a career academy did not have a higher graduation rate than lottery losers. (Both treatment and control groups had quite high graduation rates.) Kemple (2008) describes the results of the impact evaluation of career academies.
} 
Given the importance of education in contributing to economic growth and to intergenerational economic mobility, increasing the high school graduation rate in the United States is an important social objective. Yet the evidence on how to accomplish this is remarkably thin. In my view, several factors contribute to the paucity of the evidence. First, although there are numerous initiatives to improve the performance of schools, only a few are implemented in a manner that supports a defensible impact evaluation. Even rarer are evaluations that follow students long enough to assess impacts on high school graduation rates.

Second, most impact evaluations are poorly designed. Evidence of this comes from the What Works clearinghouse (WWC), which was created by the Institute of Education Sciences in 2002 to evaluate evidence on the effectiveness of education programs, practices, and policies and to make its conclusions publicly available on its website. As of October 2010, the WWC had reviewed 231 studies of dropout prevention interventions. Of these, only twenty-seven met the WWC evidence standards, with or without reservations. ${ }^{81}$ Among evaluations of dropout prevention programs that did meet WWC evidentiary standards, most were underpowered, and consequently could not detect modest effects of interventions on graduation rates.

Third, most interventions that lend themselves to strong impact evaluations are modest and modular in nature, such as introducing an additional remedial course to improve the literacy skills of struggling ninth graders. Such interventions are relatively easy to implement because only a few teachers need to be trained and then assigned to teach groups of struggling students for an hour a day. They are also relatively easy to evaluate with a random assignment design, especially when there is excess demand for the new treatment. The problem with such modest interventions is that they do not

\footnotetext{
${ }^{81}$ See Institute of Education Sciences (2011) for a description of the WWC evidence standards. A staff member at the WWC help desk provided the number of studies who met the evidence standards (October 19, 2010).
} 
change the daily experiences of struggling students in any fundamental way and consequently have little or no effect on graduation rates.

In contrast, ambitious interventions that seek to transform the daily experiences of all teachers and students in a high school are very difficult to implement. Although the successful school-wide reform efforts may share common principles, like the importance of strong leadership and the importance of changing the school culture, the details of the intervention are typically worked out over time and tend to be somewhat idiosyncratic and difficult to replicate. The story of Brockton High School, the largest public high school in Massachusetts, serving more than four-thousand students, two-thirds of whom come from low-income families, illustrates this point.

As described by Sam Dillon in the September 27, 2010, issue of the New York Times, one in three students who attended Brockton High in the late 1990s failed to graduate. Moreover, the graduation rate would fall if student performance did not improve because a large percentage of Brockton High tenth graders were failing the state's English language arts and mathematics examinations. Beginning with those who entered Grade 9 in September 2000, Massachusetts students needed to pass these examinations to obtain a high school diploma. (For more details, see Ferguson et al. (2010).)

Determined to turn the school around, a small group of teachers began meeting on Saturday mornings to devise a plan of action. At the center of the resulting reform effort was a literacy initiative, that engaged students in writing in every class, including gym, and all teachers would grade student writing using a school-wide rubric. Other elements included a redesign of the teacher evaluation system and close monitoring of student progress. Undaunted by resistance from some teachers, the core group of reformers built support for their improvement plan over several years and drove out the minority of teachers who did not want to participate. The reform effort led to significant 
improvement in student performance on the state exit examinations and to increases in the graduation rate.

The Brockton High story is inspiring. It proves that it is possible to improve the performance of high schools serving large percentages of low-income, low-achieving students. However, it does not provide a blueprint for doing so. Moreover, evaluating the impact of school-wide reform efforts like these is difficult both because it typically takes several years to define and implement the interventions, and because it is challenging to develop compelling estimates of the counterfactual outcomes.

In summary, clearly defined modular interventions that are relatively easy to implement and evaluate tend to have little or no effect on high school graduation rates because they do not alter students' fundamental experience of school. Whole school reform efforts show more promise. However, they are difficult to implement and sustain, and progress is not based on implementing a clear set of instructions. Consequently, it is difficult to define what the intervention is, and consequently what the lessons for policy are. Typically the lessons from such school-wide reforms are described in terms of the importance of strong leadership, improving instruction, increasing support for students, and changing the school culture. While few educators or policymakers would disagree with these principles, they do not lend themselves to clear guidance about what educators should do.

A different, although complementary approach to increasing high school graduation rates is to alter the conditions and incentives under which educators and students operate. Examples of relevant policies include standards-based educational reforms, charter school legislation, and the design competition for new small high schools that New York City introduced. Such policies seem promising to most economists because of their attention to incentives. However, evaluating their 
impacts on high school graduation rates is difficult because the standards-based educational systems and charter school regulations vary significantly across states, and consequently the impacts on students and educators are likely to differ. Also, there is evidence of varied effects of particular standards-based reform systems, with schools that have significant teaching capacity improving their performance and other schools resorting to "drill and kill" instruction that may increase scores on high stakes tests but does not prepare students well for life after graduation (Elmore, 2004; Supovitz, 2009).

Fortunately, a number of advances have made it increasingly possible to conduct credible causal evaluations of policy changes that affect whole schools, or school districts, or in some cases, even states. These include policy interventions that assign children to treatments on the basis of lotteries or other well-defined criteria (such as test scores), increasing openness to evaluations in which whole schools are randomly assigned to interventions, and improvements in administrative data collection that reduce the cost of long-term follow-ups. Nonetheless, there is still much to be learned about the design and implementation of policies that will result in increased graduation rates for students, especially those from economically disadvantaged backgrounds.

\section{Summing Up}

As stated at the beginning of this paper, the high school graduation rate in the United States stagnated during the last three decades of the twentieth century. The explanation does not lie in a lack of economic incentives to complete high school. To the contrary, as a result of changes in the structure of the economy, the economic incentives increased during the 1980s and 1990s.

At least part of the explanation for the stagnation in high school graduation rates lies in increases in the noneconomic costs of obtaining a high school diploma that most affect students with weak academic preparation. The catalyst for increasing high school graduation requirements was a 
concern about the quality of the labor force, which first arose in the mid-1970s and which has intensified. The concern led states to increase requirements for earning a high school diploma.

An assumption implicit in state education policies is that the quality of schooling will improve sufficiently enough to enable high school graduation rates to rise even as graduation requirements are stiffened. Indeed, many states increased public expenditures on public education to facilitate this improvement. However, it has proven much more difficult to improve school quality than to legislate increases in graduation requirements. One reason is that a large percentage of the economically disadvantaged students most affected by the increased graduation requirements enter school with weak cognitive and socioemotional skills, which tend to trail them throughout their school careers. A second is that economically disadvantaged students tend to be concentrated in a subset of the nation's schools where peer group influences hinder a positive learning environment. A third is the difficulty in attracting skilled teachers to work in schools serving high percentages of economically disadvantaged students. A fourth is that conventional comprehensive high schools do not engage the interest and effort of many teenagers, especially those who enter with weak skills. A fifth is the use of the GED option by a significant number of students, particularly black and Hispanic students, in some cases with encouragement from high school staff.

Increasing the high school graduation rate will require a set of complementary investments and structural changes in the education system. Investments aimed at improving the school readiness of economically disadvantaged children are critical, as are policies to increase the quality of teaching in schools serving high concentrations of poor children so they do not enter ninth grade without the skills and behaviors to succeed in high school. Finally, as Lyche (2010) concludes in a review of factors affecting high school graduation rates in OECD countries, it seems important to create a variety of high school options for students, including ones that provide significant experiences in 
workplace settings and clear connections between the skills students are asked to master and access to jobs that make use of these skills.

Analysts differ in their assessments of the promise of particular structural changes and policies to improve educational options for economically disadvantaged students - a group with an especially low graduation rate. Some advocate an increased role for charter schools. Others recommend the use of vouchers to stimulate a larger role for the private sector. Others see promise in standards-based educational reforms aimed at improving the accountability of traditional public schools. Yet others recommend development of more secondary education programs that have a career and technical education orientation. In my view, the evidence at this point is not clear-cut, and, in any case, the alternatives are not mutually exclusive.

A critical question to explore in future research is why the high school graduation rate increased substantially during the first decade of the twenty-first century, with the increase particularly large for black and Hispanic students. Understanding the answer to this question may be critical to the design of policies to sustain and accelerate the increase. In addition to this central question, my review of the evidence suggests several other questions that are important to address in future research.

1. Why did the high school graduation rate increase more in some states than in others between 2000 and 2010?

2. Why is there a substantial gender gap favoring females in high school graduation rates, with the gap particularly large among black and Hispanic youth?

3. How will the adoption of Common Core State Standards in mathematics and English language arts, which are significantly more academically demanding than the current standards in most states, affect high school graduation rates? 
4. How will the introduction of more difficult GED examinations that are aligned with Common Core State Standards affect high school graduation rates?

Learning the answers to these questions will likely shed considerable light on the extent to which the myriad educational reforms are improving the education of the nation's youth and contributing to the human capital needed to fuel future economic growth. 
Table 1

Outcomes for Massachusetts public school students in graduating class of 2009 who entered ninth grade for first time in September 2005; $N=77,190$.

(1)

(2)

(3)

(4)

(5)

(6)

(7)

\begin{tabular}{|c|c|c|c|c|c|c|c|}
\hline \multirow[b]{4}{*}{ Category } & \multirow{3}{*}{$\begin{array}{l}\text { On-Time } \\
\text { Graduate }\end{array}$} & \multirow[b]{2}{*}{ HS } & \multirow[b]{2}{*}{ HS } & \multirow[b]{3}{*}{ Known non- } & \multirow[b]{4}{*}{ Transfer } & \multirow[b]{4}{*}{ Unknown } & \multirow{2}{*}{$\begin{array}{l}\text { On-Time } \\
\text { graduate }\end{array}$} \\
\hline & & & & & & & \\
\hline & & Graduate & Graduate & & & & (U.S.DOE \\
\hline & (4 yrs.) & (in 5 yrs.) & (in 6 yrs.) & graduate & & & def.) \\
\hline All students $(N=77,910)$ & $76.2 \%$ & $2.2 \%$ & $0.4 \%$ & $10.8 \%$ & $9.8 \%$ & $0.7 \%$ & $84.4 \%$ \\
\hline Male $(N=39,923)$ & $73.0 \%$ & $2.8 \%$ & $0.4 \%$ & $12.5 \%$ & $10.3 \%$ & $0.9 \%$ & $81.4 \%$ \\
\hline Female $(N=37,981)$ & $79.5 \%$ & $1.6 \%$ & $0.3 \%$ & $9.0 \%$ & $9.2 \%$ & $0.6 \%$ & $87.5 \%$ \\
\hline & & & & $0.0 \%$ & & & \\
\hline African-American $(N=6,765)$ & $62.1 \%$ & $4.2 \%$ & $0.8 \%$ & $17.1 \%$ & $14.5 \%$ & $1.2 \%$ & $72.6 \%$ \\
\hline Asian-American $(N=3,489)$ & $78.4 \%$ & $2.0 \%$ & $0.2 \%$ & $6.9 \%$ & $11.8 \%$ & $0.7 \%$ & $88.8 \%$ \\
\hline
\end{tabular}




\begin{tabular}{|c|c|c|c|c|c|c|c|}
\hline Hispanic $(N=10,039)$ & $54.2 \%$ & $4.1 \%$ & $0.9 \%$ & $23.6 \%$ & $16.3 \%$ & $0.9 \%$ & $64.8 \%$ \\
\hline White $(N=56,392)$ & $81.7 \%$ & $1.6 \%$ & $0.2 \%$ & $8.0 \%$ & $7.9 \%$ & $0.6 \%$ & $88.7 \%$ \\
\hline Black female $(N=3,280)$ & $69.0 \%$ & $2.9 \%$ & $0.7 \%$ & $13.1 \%$ & $13.2 \%$ & $1.0 \%$ & $79.5 \%$ \\
\hline Black male $(N=3,485)$ & $55.6 \%$ & $5.4 \%$ & $0.9 \%$ & $20.9 \%$ & $15.8 \%$ & $1.4 \%$ & $65.9 \%$ \\
\hline Asian female $(N=1,651)$ & $81.5 \%$ & $1.2 \%$ & $0.0 \%$ & $5.8 \%$ & $10.8 \%$ & $0.7 \%$ & $91.4 \%$ \\
\hline Asian male $(N=1,837)$ & $75.5 \%$ & $2.8 \%$ & $0.4 \%$ & $8.0 \%$ & $12.6 \%$ & $0.8 \%$ & $86.4 \%$ \\
\hline Hispanic female $(N=4,887)$ & $59.3 \%$ & $3.5 \%$ & $0.7 \%$ & $20.4 \%$ & $15.6 \%$ & $0.6 \%$ & $70.3 \%$ \\
\hline Hispanic male $(N=5,150)$ & $49.4 \%$ & $4.7 \%$ & $1.0 \%$ & $26.7 \%$ & $16.9 \%$ & $1.2 \%$ & $59.4 \%$ \\
\hline White female $(N=27,531)$ & $84.2 \%$ & $1.1 \%$ & $0.2 \%$ & $6.6 \%$ & $7.4 \%$ & $0.5 \%$ & $91.0 \%$ \\
\hline White male $(N=28,859)$ & $79.3 \%$ & $2.1 \%$ & $0.3 \%$ & $9.3 \%$ & $8.3 \%$ & $0.8 \%$ & $86.4 \%$ \\
\hline
\end{tabular}

Source: Author's tabulations of longitudinal data provided by the Massachusetts Department of Elementary and Secondary Education. 
Table 2. High school outcomes for on-time entrants and late entrants to the 2009 graduation cohort of an urban and a suburban Massachusetts public high school.
(1)
(2)
(3)
(4)
(5)
(6)
(7)

On-Time HS

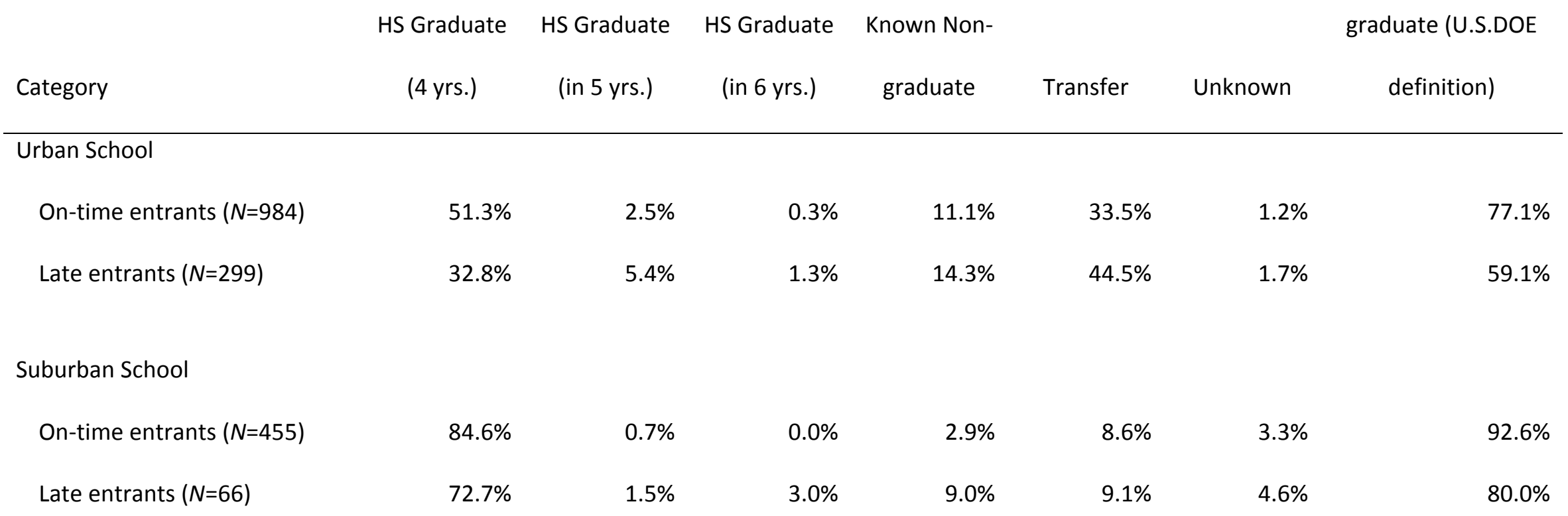


Source: Author's tabulations of longitudinal data provided by the Massachusetts Department of Elementary and Secondary Education. 
Table 3: Adjusted status completion rates of twenty- to twenty-four-year-olds, by gender and race, and birth year range

\begin{tabular}{|c|c|c|c|c|c|c|c|c|c|}
\hline & $1946-$ & $1951-$ & $1956-$ & $1961-$ & $1966-$ & $1971-$ & $1976-$ & 1981- & 1986- \\
\hline Year of Birth Range & 1950 & 1955 & 1960 & 1965 & 1970 & 1975 & 1980 & 1985 & 1990 \\
\hline \multicolumn{10}{|c|}{ Year in which group was } \\
\hline aged 20-24 & 1970 & 1975 & 1980 & 1985 & 1990 & 1995 & 2000 & 2005 & 2010 \\
\hline \multicolumn{10}{|l|}{ Males and Females } \\
\hline All Races & $80.8 \%$ & $81.0 \%$ & $78.6 \%$ & $78.6 \%$ & $78.5 \%$ & $78.9 \%$ & $77.6 \%$ & $81.8 \%$ & $83.7 \%$ \\
\hline Whites & $83.8 \%$ & $84.2 \%$ & $81.7 \%$ & $81.8 \%$ & $82.0 \%$ & $82.7 \%$ & $81.8 \%$ & $84.5 \%$ & $86.3 \%$ \\
\hline Blacks & $63.7 \%$ & $69.1 \%$ & $68.0 \%$ & $69.4 \%$ & $69.0 \%$ & $71.6 \%$ & $68.0 \%$ & $75.2 \%$ & $78.2 \%$ \\
\hline Hispanics & $58.6 \%$ & $64.6 \%$ & $65.2 \%$ & $59.8 \%$ & $60.2 \%$ & $62.4 \%$ & $63.9 \%$ & $74.3 \%$ & $77.8 \%$ \\
\hline \multicolumn{10}{|l|}{ Hispanics, including } \\
\hline immigrants & $56.6 \%$ & $54.5 \%$ & $56.8 \%$ & $50.8 \%$ & $51.4 \%$ & $50.8 \%$ & $53.3 \%$ & $63.9 \%$ & $71.0 \%$ \\
\hline \multicolumn{10}{|l|}{ Males } \\
\hline All Races & $80.8 \%$ & $80.6 \%$ & $76.8 \%$ & $76.5 \%$ & $76.7 \%$ & $76.2 \%$ & $74.0 \%$ & $78.5 \%$ & $80.7 \%$ \\
\hline Whites & $84.0 \%$ & $83.8 \%$ & $80.2 \%$ & $79.9 \%$ & $80.8 \%$ & $80.7 \%$ & $79.0 \%$ & $81.9 \%$ & $84.1 \%$ \\
\hline Blacks & $60.9 \%$ & $66.1 \%$ & $66.1 \%$ & $64.4 \%$ & $63.8 \%$ & $66.6 \%$ & $61.2 \%$ & $67.9 \%$ & $72.0 \%$ \\
\hline Hispanics & $60.0 \%$ & $64.0 \%$ & $64.0 \%$ & $58.7 \%$ & $57.7 \%$ & $57.1 \%$ & $59.3 \%$ & $70.4 \%$ & $74.0 \%$ \\
\hline Hispanics, including & $58.1 \%$ & $54.0 \%$ & $54.0 \%$ & $48.3 \%$ & $47.8 \%$ & $45.9 \%$ & $48.3 \%$ & $59.8 \%$ & $65.9 \%$ \\
\hline
\end{tabular}


immigrants

\section{Females}

$\begin{array}{lccccccccc}\text { All Races } & 80.7 \% & 81.4 \% & 80.5 \% & 80.7 \% & 80.3 \% & 81.7 \% & 81.2 \% & 85.1 \% & 86.9 \% \\ \text { Whites } & 83.6 \% & 84.5 \% & 83.2 \% & 83.7 \% & 83.3 \% & 84.7 \% & 84.7 \% & 87.1 \% & 88.6 \% \\ \text { Blacks } & 66.0 \% & 71.5 \% & 72.6 \% & 73.8 \% & 73.9 \% & 76.1 \% & 74.4 \% & 81.7 \% & 84.2 \% \\ \text { Hispanics } & 57.5 \% & 64.4 \% & 66.6 \% & 61.0 \% & 62.7 \% & 67.8 \% & 68.7 \% & 78.2 \% & 81.8 \% \\ \text { Hispanics, including } & & & & & & & & & \\ \text { immigrants } & 55.4 \% & 55.1 \% & 59.0 \% & 53.6 \% & 55.6 \% & 56.4 \% & 59.3 \% & 68.3 \% & 76.8 \% \\ \end{array}$

Note: Estimates for cohorts born in years 1947-1950 to 1956-1960 are taken from Heckman and LaFontaine (2010).

Author's calculations for later cohorts, using information from Census 1990, 2000, American Community Survey 2010, and

GED Testing Service data on number of individuals by race/ethnicity and age who passed GED tests in each year. Status completion

rates of cohorts born in age ranges 1946-1950, 1956-1960, 1966-1970, 1976-1980, and 1986-1990 were estimated from data on 20-24 year-olds in the relevant Census year or the 2010 ACS. Staus completion rates of cohorts born in age ranges 1951-1955, 1961-1965, 1971-1975, and 1981-1985 were estimated from data on twenty-five- to twenty-nine-year-olds in the relevant census year or the 2010 ACS. Except as noted, recent immigrants were excluded from the samples used in estimating the adjusted status completion rates. The estimates for all races include Asians,

Native Americans, and other race groups not shown separately. 
Table 4: Percentage of Massachusetts public school students in 2009 graduation cohort who repeated grade 9, and percentage of repeaters who graduated within six years

\begin{tabular}{lcc}
\hline & & Percent of Grade 9 \\
& & Repeaters with \\
& Known Outcomes \\
& Grade 9 & Who Graduated in \\
& & Six Years \\
\hline All & 9.8 & 35.2 \\
White & & 37.2 \\
Black & 6.2 & 37.7 \\
Hispanic & 21.4 & 29.0 \\
White & 24.2 & \\
& &
\end{tabular}


Males

Females

Black

Males

Females

Hispanic

Males

Females

Urban Low-Income

Source: Author's tabulations of longitudinal data provided by the Massachusetts Department of Elementary and Secondary Education. Estimates reported in this table are based on information for students who were first-time ninth graders in Massachusetts public schools in the 2005-2006 school year. 
Figure 1: U.S. High School Graduation Rate for Twenty- to Twenty-four-year olds by race/ethnicity and birth cohort

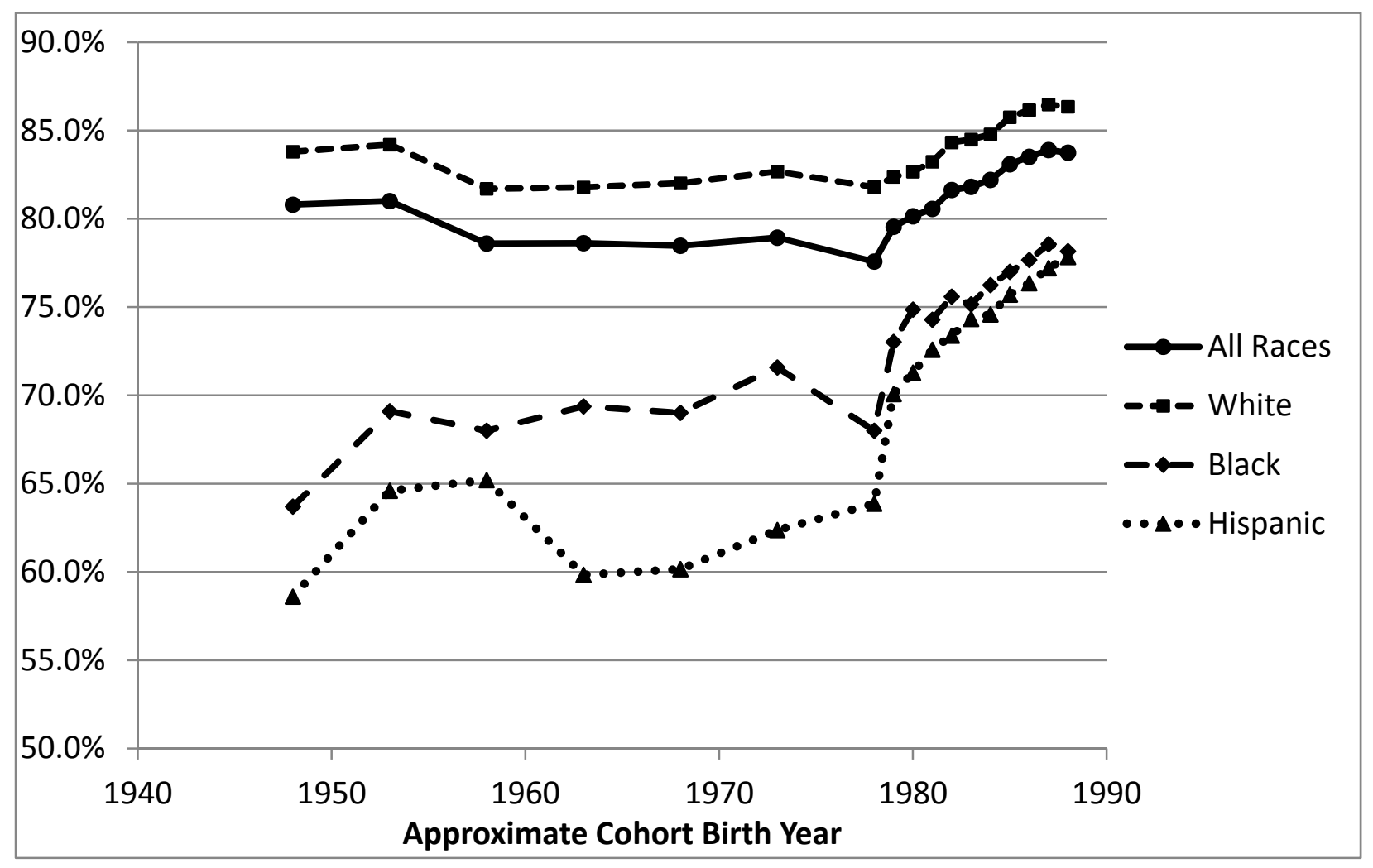


Sources: For birth cohorts 1946-1950 to 1956-1950, Heckman and LaFontaine (2010); for subsequent cohorts, author’s estimation from U.S. Census, American Community Survey, and GED Testing Service data. 


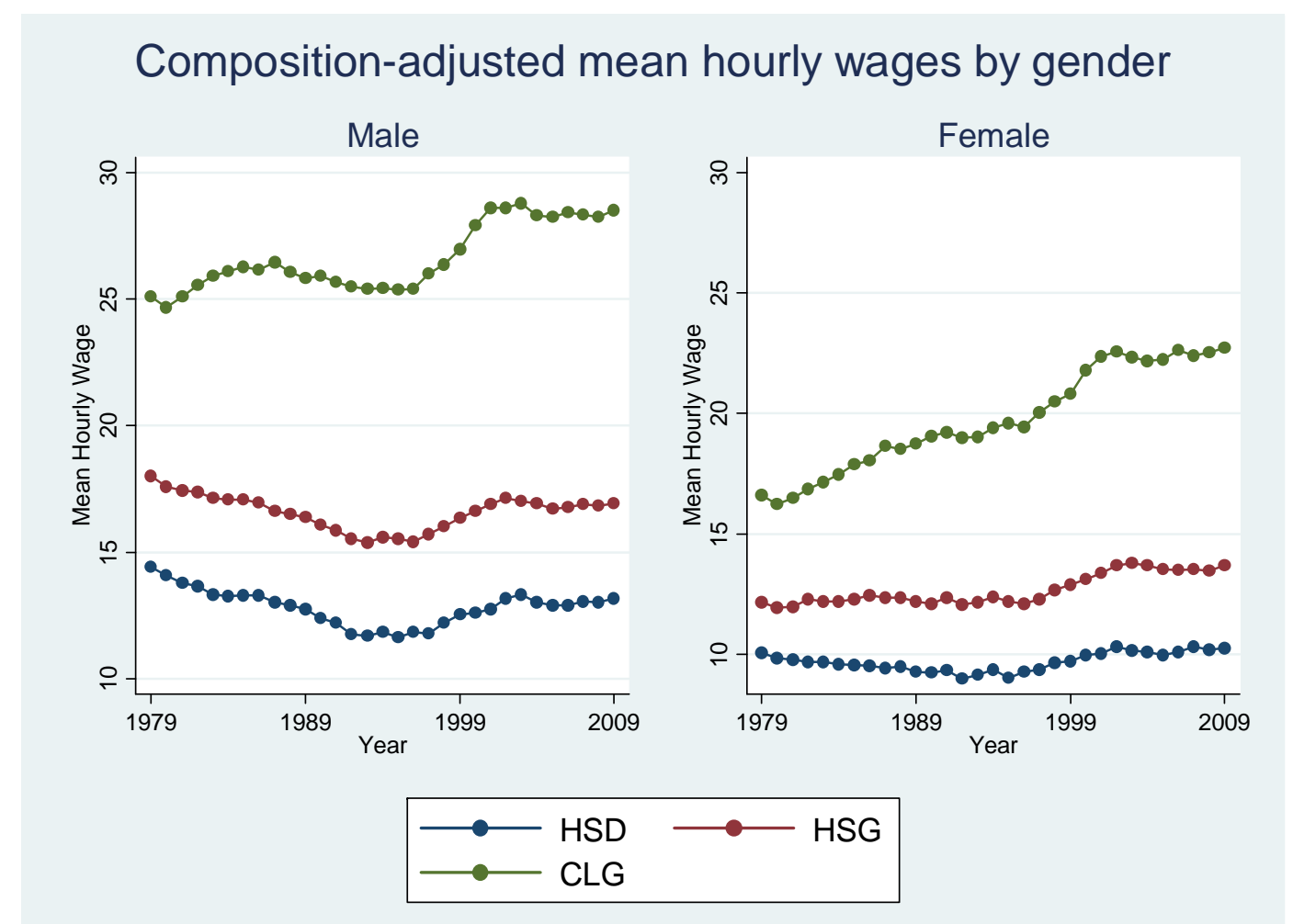

Note: HSD= high school dropout, HSG = high school graduate, CLG = four-year college graduate.

Source: Author's tabulations from Current Population Survey MORG files. GED recipients are counted as high school graduates in the MORG data. 
Figure 3: Trend (1980-2008) in the Ratio of the Average Real Wage of High School Dropouts to High School Graduates (including GED recipients) by Gender and Race/Ethnicity

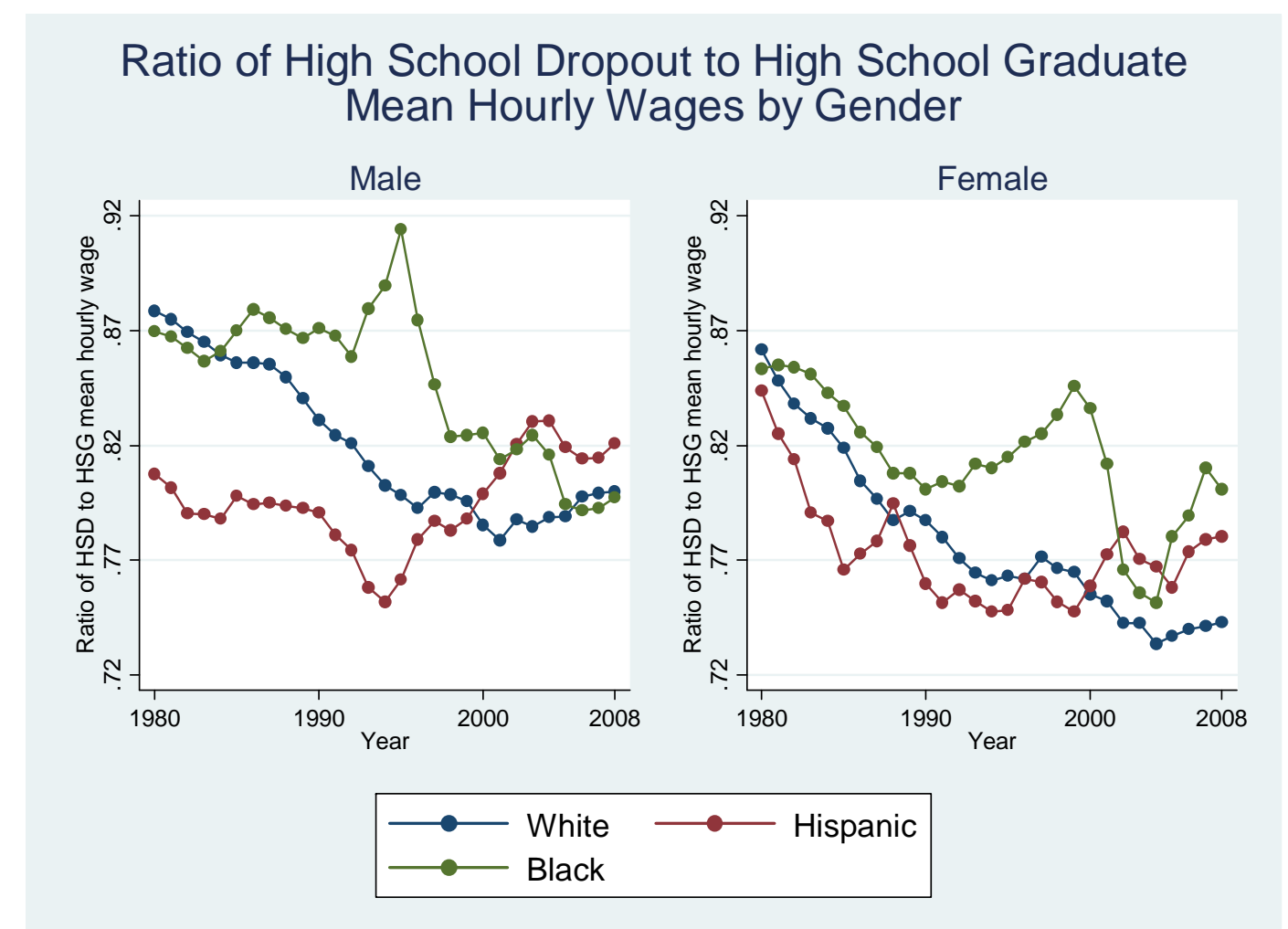

Source: Author’s tabulations from Current Population Survey MORG files. (To reduce random variation owing to small sample sizes, the real wages are expressed as three-year moving averages.) 
Figure 4: Trend (1980-2008) in the Employment to Population (EPOP) Ratio for Male and Female School Dropouts

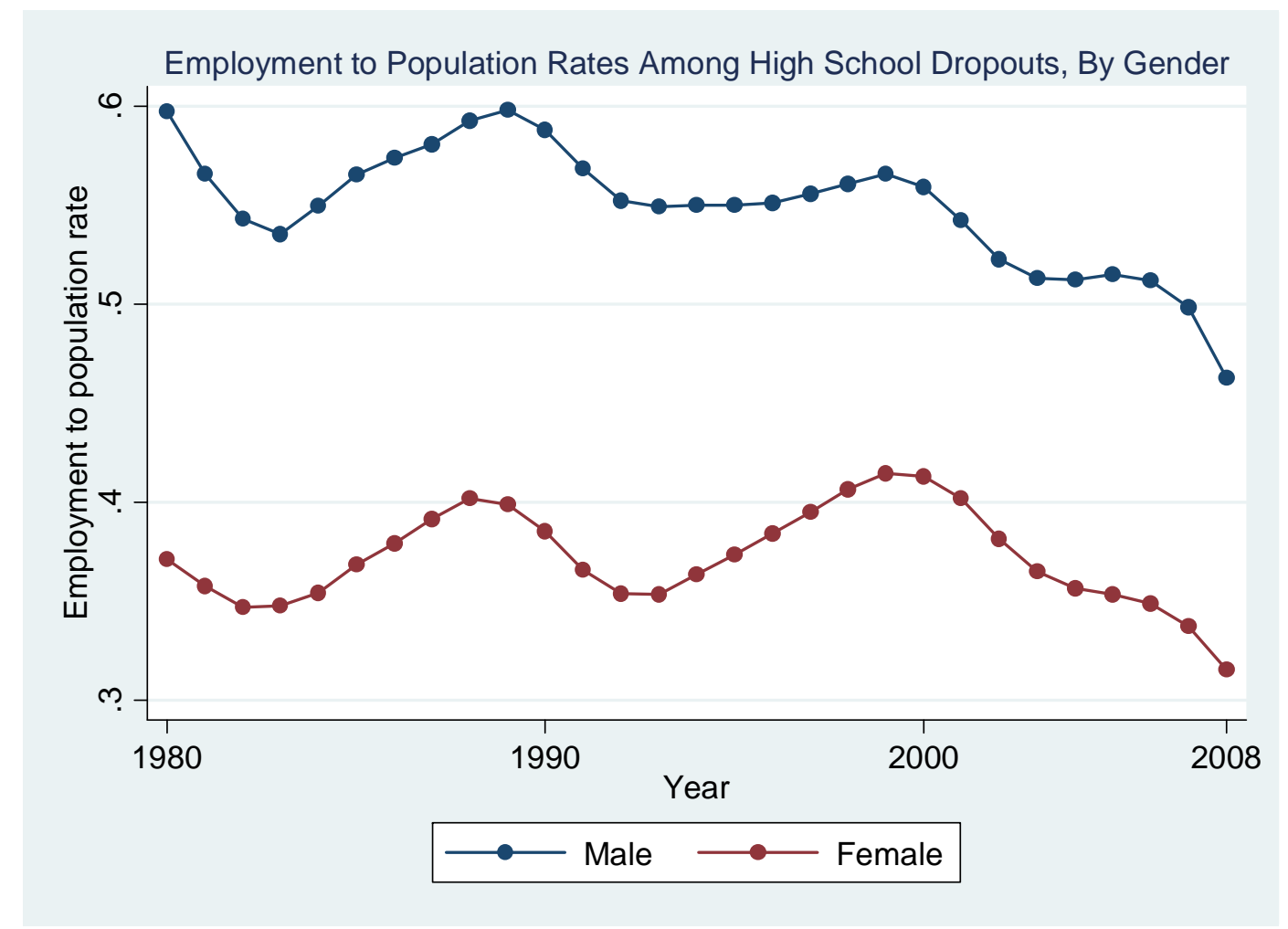

Source: Author’s tabulations from Current Population Survey MORG files. (To reduce random variation due to small sample sizes, the EPOP ratios are expressed as three-year moving averages.) 
Figure 5: Extent to Which Race-Based Gaps in High School Graduation Rates Can Be Accounted for by Differences in Low-Income Status, Grade 8 Attendance Rates, and Grade 8 Mathematics Scores.

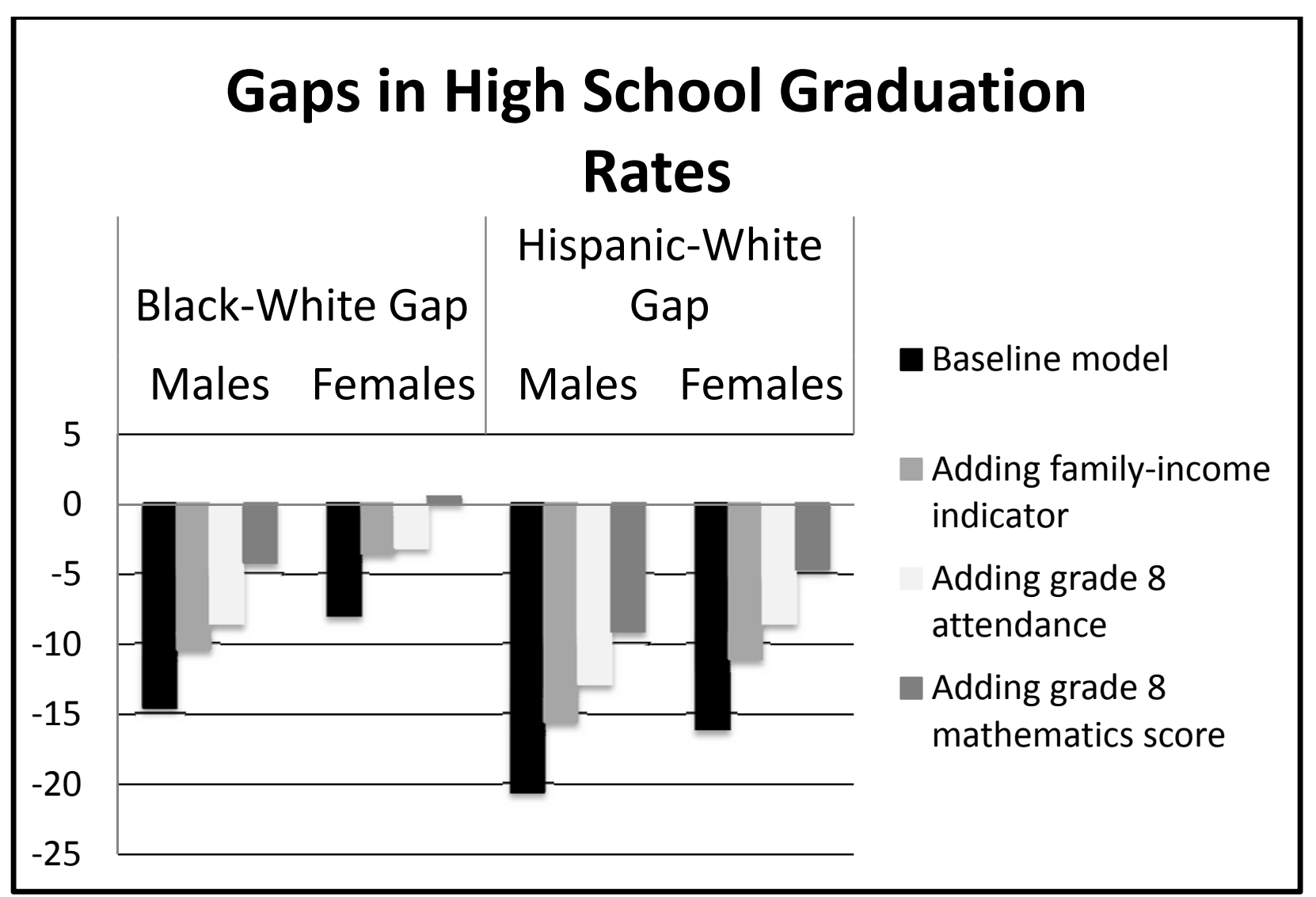


Source: Author's tabulations of data from Massachusetts Department of Elementary and Secondary Education. Graphs based on the coefficients of linear probability models in which the dichotomous outcome, graduated from high school within six years of entering Grade 9, was regressed, first, on a set of indicators for race/ethnicity-gender combinations. Then, sequentially, the following variables were added to the baseline model: an indicator of family low-income status when student was in Grade 8, Grade 8 school attendance, and score on the Grade 8 statewide standardized mathematics examination. Students who transferred from the Massachusetts public school system or for whom information on graduation status was missing were excluded from the analysis sample. 
Figure 6. NAEP Long-Term Trend Scores for Thirteen-Year-Olds Scoring in the Twenty-fifth Percentile in

Mathematics and Reading, by Race

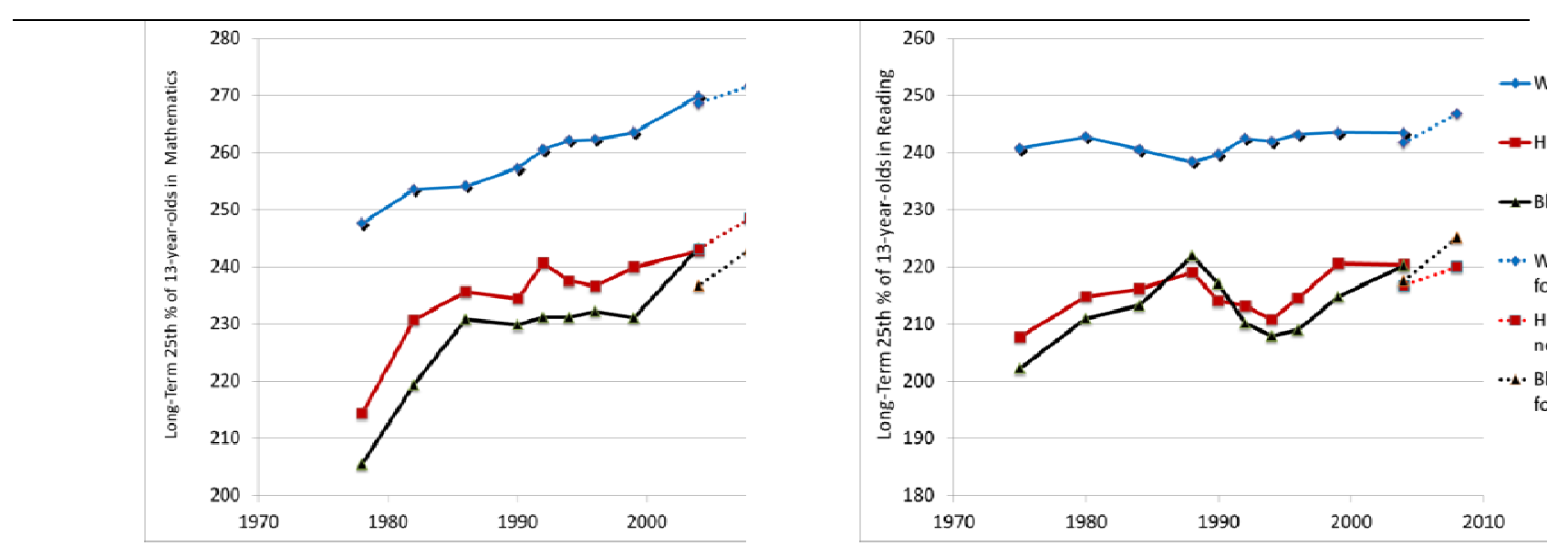

Source: Author's tabulations of data from the NAEP. 


\section{Bibliography}

Acemoglu, Daron and Joshua Angrist. 2001. "How Large are Human-Capital Externalities? Evidence from Compulsory Schooling Laws." In NBER Macroeconomics Annual 2000, edited by Ben S. Bernanke and Kenneth Rogoff eds, 9-59. Volume 15. Cambridge and London: MIT Press.

Akerlof, George A. and Rachel E. Kranton. 2000. "Economics and Identity." Quarterly Journal of Economics 115 (3): 715-753.

. 2002. "Identity and Schooling: Some Lessons for the Economics of Education." Journal of Economic Literature 40 (4): 1167-1201.

Alexander, Karl I., Doris R. Entwisle, and Carrie S. Horsey. 1997. "From First Grade Forward: Early Foundations of High School Dropout." Sociology of Education 70: 87-107.

Almond, Douglas and Janet Currie. 2011. "Human Capital Development before Age Five." In Handbook of Labor Economics, edited by Orley Ashenfelter and David Card. Vol. 4, chapter 15. Amsterdam: North Holland.

Almond, Douglas, Lena Edlund, and Marten Palme. 2009. "Chernobyl's Subclinical Legacy: Prenatal Exposure to Radioactive Fallout and School Outcomes in Sweden." Quarterly Journal of Economics 124 (4): 1729-1772.

Altonji, Joseph G. and Richard Mansfield. 2011. "The Role of Family, School and Community Characteristics in Inequality in Education and Labor Market Outcomes." In Whither Opportunity: Growing Inequality, Schools, and Children's Life Chances, edited by Greg J. Duncan and Richard J. Murnane. New York: Russell Sage Foundation and Spencer Foundation.

Angrist, Joshua D. and Alan B. Krueger. 1991. "Does Compulsory School Attendance Affect Schooling and Earnings?" Quarterly Journal of Economics 106 (4): 979-1014.

Austen-Smith, David and Roland G. Fryer Jr. 2005. "An Economic Analysis of "Acting White."." Quarterly Journal of Economics 120 (2): 551-583.

Autor, David H., Lawrence F. Katz, and Melissa S. Kearney. 2008. "Trends in U.S. Wage Inequality: Revising the Revisionists." Review of Economics and Statistics 90 (2): 300-323.

Autor, David H., Frank Levy, and Richard J. Murnane. 2003. "The Skill Content of Recent Technological Change: An Empirical Exploration." Quarterly Journal of Economics 118 (4): 1279-1333. 
Bailey, Martha J. and Susan M. Dynarski. 2011. "Inequality in Postsecondary Education." In Whither Opportunity: Growing Inequality, Schools, and Children's Life Chances, edited by Greg J. Duncan and Richard J. Murnane. New York: Russell Sage Foundation.

Balfanz, Robert, John M. Bridgeland, Mary Bruce, and Joanna Hornig Fox. 2012. Building a Grad Nation: Progress and Challenge in Ending the High School Dropout Epidemic. Baltimore: Civic Enterprises Everyone Graduates Center at Johns Hopkins University.

Balfanz, Robert, John M. Bridgeland, Laura A. Moore, and Joanna Hornig Fox. 2010. Building a Grad Nation: Progress and Challenge in Ending the High School Dropout Epidemic. Washington, D.C.: America's Promise Alliance.

Banerjee, Abhijit V. and Esther Duflo. 2011. Poor Economics : A Radical Rethinking of the Way to Fight Global Poverty. New York: PublicAffairs.

Barnett, W. Steven and Donald J. Yarosz. 2007. Who Goes to Preschool and Why does it Matter?. New Brunswick, NJ: National Institute for Early Education Research.

Barton, Paul. 2009. Chasing the High School Graduation Rate: Getting the Data we Need and using it Right. Princeton: Educational Testing Service.

Becker, Gary S. 1964. Human Capital; a Theoretical and Empirical Analysis, with Special Reference to Education,. Vol. no.80. New York,: National Bureau of Economic Research; distributed by Columbia University Press.

Becker, Gary S. and Casey B. Mulligan. 1997. "The Endogenous Determination of Time Preference." Quarterly Journal of Economics 112 (3): 729-758.

Bedard, Kelly and Chau Do. 2005. "Are Middle Schools More Effective? the Impact of School Structure on Student Outcomes." Journal of Human Resources 40 (3): 660-682.

Bedard, Kelly. 2001. "Human Capital Versus Signaling Models: University Access and High School Dropouts." Journal of Political Economy 109 (4): 749-775.

Bertrand, Marianne, Sendhil Mullainathan, and Eldar Shafir. 2004. "A Behavioral-Economics View of Poverty." American Economic Review 94 (2): 419-423.

Bertrand, Marianne and Sendhil Mullainathan. 2004. "Are Emily and Greg More Employable than Lakisha and Jamal? A Field Experiment on Labor Market Discrimination." American Economic Review 94 (4): 991-1013.

Bertrand, Marianne and Jessica Pan. 2013. "The Trouble with Boys: Social in!Uences and the Gender Gap in Disruptive Behavior." American Economic Journal. Applied Economics 5 (1): 1-35. 
Bettinger, Eric and Robert Slonim. 2007. "Patience among Children." Journal of Public Economics 91 (1-2): 343-363.

Betts, Julian R. and Robert B. Costrell. 2001. "Incentives and Equity Under Standards-Based Reform." In Brookings Papers on Education Policy: 2001, edited by Diane Ravitch. Washington, D.C.: Brookings Institution.

Betts, Julian R. 1998. "The Impact of Educational Standards on the Level and Distribution of Earnings." American Economic Review 88 (1): 266-275.

Bishop, John H., Ferran Mane, Michael Bishop, and Joan Moriarty. 2001. "The Role of End-ofCourse Exams and Minimal Competency Exams in Standards-Based Reforms." In Brookings Papers in Education Policy 2001, edited by Diane Ravitch. Washington, D.C.: Brookings.

Black, Dan A., Terra G. McKinnish, and Seth G. Sanders. 2005. "Tight Labor Markets and the Demand for Education: Evidence from the Coal Boom and Bust." Industrial and Labor Relations Review 59 (1): 3-16.

Bloom, Howard S., Saskia Levy Thompson, and Rebecca Unterman. 2010. Transforming the High School Experience: How New York City's New Small Schools are Boosting Student Achievement and Graduation Rates. New York: MDRC.

Bloom, Howard S. and Rebecca Unterman. 2012. Sustained Positive Effects on Graduation Rates Produced by New York City's Small Public High Schools of Choice. New York City: MDRC Policy Brief.

Bond, Timothy N. and Kevin Lang. in press. "The Evolution of the Black-White Test Score Gap in Grades K-3: The Fragility of Results." Review of Economics and Statistics.

Bozick, Robert and Erich Lauff. 2007. Education Longitudinal Study of 2002 (ELS:2002): A First Look at the Initial Postsecondary Experiences of the Sophomore Class of 2002. Washington, D.C.: National Center for Education Statistics, Institute of Education Sciences, U.S. Department of Education.

Cameron, Stephen V. and James J. Heckman. 1993. "The Nonequivalence of High School Equivalents." Journal of Labor Economics 11 (1): 1-47.

Cameron, Stephen V. and James J. Heckman. 2001. "The Dynamics of Educational Attainment for Black, Hispanic, and White Males." Journal of Political Economy 109 (3): 455-499.

— 1998. "Life Cycle Schooling and Dynamic Selection Bias: Models and Evidence for Five Cohorts of American Males." Journal of Political Economy 106 (2): 262-333.

Card, David. 2009. "Richard T. Ely Lecture: Immigration and Inequality." American Economic Review 99 (2): 1-21. 
Cascio, Elizabeth U. 2009. Do Investments in Universal Early Education Pay Off? Long-Term Effects of Introducing Kindergartens into Public Schools. Cambridge, MA: working paper no. 14951, National Bureau of Economic Research.

Castillo, Marco, Paul J. Ferraro, Jeffrey L. Jordan, and Ragan Petrie. 2011. "The Today and Tomorrow of Kids: Time Preferences and Educational Outcomes of Children." Journal of Public Economics 95 (11-12): 1377-1385.

Chapman, Chris, Jennifer Laird, Nicole Ifill, and Angelina KewalRamani. 2011. Trends in High School Dropout and Completion Rates in the United States: 1972-2009. Washington DC: National Center for Education Statistics, U.S. Department of Education.

Charles, Kerwin Kofi and Ming Ching Luoh. 2010. "Male Incarceration, the Marriage Market, and Female Outcomes." Review of Economics and Statistics 92 (3): 614-627.

Chetty, Raj, John N. Friedman, Nathaniel Hilger, Emmanuel Saez, Diane Schanzenbach, and Danny Yagan. 2011. "How does Your Kindergarten Classroom Affect Your Earnings? Evidence from Project STAR." Quarterly Journal of Economics 126 (4): 1593-1660.

Chetty, Raj, John N. Friedman, and Jonah H. Rockoff. 2011. The Long-Term Impacts of Teachers: Teacher Value-Added and Student Outcomes in Adulthood. Cambridge, MA: working paper no. 17699, National Bureau of Economic Research.

Clotfelter, Charles T., Helen F. Ladd, and Jacob L. Vigdor. 2009. "The Academic Achievement Gap in Grades 3 to 8." Review of Economics and Statistics 91 (2): 398-419.

Coleman, James S. and Thomas Hoffer. 1987. Public and Private High Schools : The Impact of Communities. New York: Basic Books.

Cunha, Flavio, James J. Heckman, Lance J. Lochner, and Dimitriy V. Masterov. 2006. "Interpreting the Evidence on Life Cycle Skill Formation " In Handbook of the Economics of Education, edited by Eric A. Hanushek and Finis Welch. Vol. 1. Amsterdam: Elsevier.

Cunha, Flavio, James Heckman, and Susanne Schennach. 2010. "Estimating the Technology of Cognitive and Noncognitive Skill Formation." Econometrica 78 (3): 883-931.

Cunha, Flavio and James J. Heckman. 2008. "Symposium on Noncognitive Skills and their Development: Formulating, Identifying and Estimating the Technology of Cognitive and Noncognitive Skill Formation." Journal of Human Resources 43 (4): 738-782.

Cunha, Flavio and James Heckman. 2007. "The Technology of Skill Formation." American Economic Review 97 (2): 31-47.

Dee, Thomas S. and Brian A. Jacob. 2007. "Do High School Exit Exams Influence Educational Attainment Or Labor Market Performance?" In Standards-Based Reform and Children in 
Poverty: Lessons for "no Child Left Behind" , edited by Adam Gamoran. Washington, DC: Brookings Institution Press.

Deming, David J. 2011. "Better Schools, Less Crime?" Quarterly Journal of Economics 126 (4): 2063-2115.

Deming, David, Justine S. Hastings, Thomas J. Kane, and Douglas O. Staiger. 2011. School Choice, School Quality and Academic Achievement. working paper, Harvard Graduate School of Education, Cambridge, MA.:.

Deming, David. 2009. "Early Childhood Intervention and Life-Cycle Skill Development: Evidence from Head Start." American Economic Journal: Applied Economics 1 (3): 111134.

Dillon, Sam. 2010. "4,100 Students Prove 'Small is Better' Rule Wrong." New York Times, 1.

Duncan, Greg J. and Katherine Magnuson. 2011. "The Nature and Impact of Early Achievement Skills, Attention Skills, and Behavior Problems." In Whither Opportunity? Rising Inequality, Schools, and Children's Life Chances, edited by Greg J. Duncan and Richard J. Murnane, 47-70. New York: Russell Sage and Spencer Foundations.

Eckstein, Zvi and Kenneth I. Wolpin. 1999. "Why Youths Drop Out of High School: The Impact of Preferences, Opportunities, and Abilities." Econometrica 67 (6): 1295-1339.

Elmore, Richard F. 2004. School Reform from the Inside Out: Policy, Practice, and Performance. Cambridge, MA: Harvard Education Press.

Evans, William N., Craig Garthwaite, and Timothy J. Moore. 2012. The White/Black Educational Gap, Stalled Progress, and the Long Term Consequences of the Emergence of Crack Cocaine Markets. Cambridge, MA: working paper no. 18437, National Bureau of Economic Research.

Ferguson, Ronald F., Sandra Hackman, Robert Hanna, and Ann Ballantine. 2010. How High Schools Become Exemplary: Ways that Leadership Raises Achievement and Narrows Gaps by Improving Instruction in 15 Public High Schools. Cambridge MA: The Achievement Gap Initiative at Harvard University.

Finn, Jeremy D., Susan B. Gerber, and Jayne Boyd-Zaharias. 2005. "Small Classes in the Early Grades, Academic Achievement, and Graduating from High School." Journal of Educational Psychology 97 (2): 214-223.

Frederick, Shane, George Loewenstein, and Ted O'Donoghue. 2002. "Time Discounting and Time Preference: A Critical Review." Journal of Economic Literature 40 (2): 351-401.

Fryer, Roland G., Jr and Steven D. Levitt. 2004. "Understanding the Black-White Test Score Gap in the First Two Years of School." Review of Economics and Statistics 86 (2): 447-464. 
Fryer, Roland G., Paul S. Heaton, Steven D. Levitt, and Kevin M. Murphy. in press. "Measuring Crack Cocaine and its Impact." Economic Inquiry.

Fryer, Roland G.,Jr and Steven D. Levitt. 2006. "The Black-White Test Score Gap through Third Grade." American Law and Economics Review 8 (2): 249-281.

Furstenberg, Frank F. 2011. "The Challenges of Finding Causal Links between Family Educational Practices and Schooling Outcomes." In Whither Opportunity? Rising Inequality, Schools, and Children's Life Chances, edited by Greg J. Duncan and Richard J. Murnane, 465-482: Russell Sage Foundation and the Spencer Foundation.

Garces, Eliana, Duncan Thomas, and Janet Currie. 2002. "Longer-Term Effects of Head Start." American Economic Review 92 (4): 999-1012.

GED Testing Service. 2012. 2011 Annual Statistical Report on the GED Test.

Goldin, Claudia D. and Lawrence F. Katz. 2008. The Race between Education and Technology. Cambridge, Mass.: Belknap Press of Harvard University Press.

Goldman, Susan R. 2012. "Adolescent Literacy: Learning and Understanding Content." The Future of Children 22 (2): 89-116.

Gormley, William T. Jr, Deborah Phillips, and Ted Gayer. 2008. "Preschool Programs can Boost School Readiness." Science 320 (5884): 1723-1724.

Guryan, Jonathan. 2004. "Desegregation and Black Dropout Rates." American Economic Review 94 (4): 919-943.

Hanushek, Eric A. and Steven G. Rivkin. 2009. "Harming the Best: How Schools Affect the Black-White Achievement Gap." Journal of Policy Analysis and Management 28 (3): 366393.

Hanushek, Eric A. and Ludger Woessmann. 2008. "The Role of Cognitive Skills in Economic Development." Journal of Economic Literature 46 (3): 607-668.

Hauser, Robert M. and Judy A. Koenig, eds. 2011. High School Dropout, Graduation, and Completion Rates: Better Data, Better Measures, Better Decisions. Washington, DC: National Academies Press.

Havnes, Tarjei and Magne Mogstad. 2011. "No Child Left Behind: Subsidized Child Care and Children's Long-Run Outcomes." American Economic Journal: Economic Policy 3 (2): 97129.

Heckman, James J. 2011. "The American Family in Black \& White: A Post-Racial Strategy for Improving Skills to Promote Equality." Daedalus 140 (2): 70-89. 
Heckman, James J., John E. Humphries, and Nicholas S. Mader. 2011. "The GED." In Handbook of the Economics of Education, edited by Eric A. Hanushek, Stephen J. Machin and Ludger Woessmann. Vol. 3, 423-484. Amsterdam: North Holland Elsevier.

Heckman, James J., John Eric Humphries, Paul A. LaFontaine, and Pedro L. Rodriguez. 2012. "Taking the Easy Way Out: How the GED Testing Program Induces Students to Drop Out." Journal of Labor Economics 30 (4): 495-520.

Heckman, James J. and Paul A. LaFontaine. 2010. "The American High School Graduation Rate:Trends and Levels." Review of Economics and Statistics 92 (2): 244-262.

Heckman, James J., Lance J. Lochner, and Petra E. Todd. 2006. "Earnings Functions, Rates of Return and Treatment Effects: The Mincer Equation and Beyond." In Handbook of the Economics of Education, edited by Eric A. Hanushek and Finis Welch. Vol. 1. Amsterdam: Handbook of the Economics of Education.

Heckman, James J. and Paul A. LaFontaine. 2006. "Bias-Corrected Estimates of GED Returns." Journal of Labor Economics 24 (3): 661-700.

Heckman, James J., Lance J. Lochner, and Petra E. Todd. 2008. "Earnings Functions and Rates of Return." Journal of Human Capital 2 (1): 1-31.

Heckman, James J., Seong Hyeok Moon, Rodrigo Pinto, Peter A. Savelyev, and Adam Yavitz. 2010. "The Rate of Return to the HighScope Perry Preschool Program." Journal of Public Economics 94 (1-2): 114-128.

Heckman, James J. and Yona Rubinstein. 2001. "The Importance of Noncognitive Skills: Lessons from the GED Testing Program." American Economic Review 91 (2): 145-149.

Heckman, James J. 2008. "Schools, Skills, and Synapses." Economic Inquiry 46 (3): 289-324.

Heckman, James J., Jora Stixrud, and Sergio Urzua. 2006. "The Effects of Cognitive and Noncognitive Abilities on Labor Market Outcomes and Social Behavior." Journal of Labor Economics 24 (3): 411-482.

Ho, Andrew D. 2008. "The Problem with "proficiency": Limitations of Statistics and Policy Under no Child Left Behind." Educational Researcher 37 (6): 351-360.

Ingels, Steven J., Thomas R. Curtin, Philip Kaufman, Martha N. Alt, and Xianglei Chen. 2002. Coming of Age in the 1990s: The Eighth-Grade Class of 198812 Years Later. Washington, DC: U.S. Department of Education, National Center for Education Statistics.

Institute of Education Sciences. 2011. What Works Clearinghouse: Procedures and Standards Handbook (Version 2.1). Washington, DC: U.S. Department of Education. 
Jacob, Brian A. 2001. "Getting Tough? the Impact of High School Graduation Exams." Educational Evaluation \& Policy Analysis 23 (2): 99-121.

Jepsen, Christopher, Peter Mueser, and Kenneth Troske. 2010. "Labor-Market Returns to the GED using Regression Discontinuity Analysis." Paper Presented at the November 2010 Meetings of the Association of Public Policy Analysis and Management.

Jepsen, Christopher and Steven Rivkin. 2009. "Class Size Reduction and Student Achievement: The Potential Tradeoff between Teacher Quality and Class Size." Journal of Human Resources 44 (1): 223-250.

Johnson, Rucker C. 2011. Long-Run Impacts of School Desegregation \& School Quality on Adult Attainments. Cambridge, MA: working paper no. 16664, National Bureau of Economic Research.

Kemple, James J., Corinne M. Herlihy, and Thomas J. Smith. 2005. Making Progress Toward Graduation: Evidence from the Talent Development High School Model.

Kemple, James J. 2008. Career Academies: Long-Term Impacts on Labor Market Outcomes, Educational Attainment, and Transitions to Adulthood. New York: MDRC.

Kirk, David S. and Robert J. Sampson. 2011. "Crime and the Production of Safe Schools." In Whither Opportunity: Growing Inequality, Schools, and Children's Life Chances, edited by Greg J. Duncan and Richard J. Murnane. New York: Russell Sage Foundation.

Kreider, Rose M. and Renee Ellis. 2011. Living Arrangements of Children: 2009," Current Population Reports, P70-126. Washington, DC, 2011: U.S. Census Bureau.

Lang, Kevin. 2007. Poverty and Discrimination. Princeton, N.J.: Princeton University Press.

Lang, Kevin and Paul A. Ruud. 1986. "Returns to Schooling, Implicit Discount Rates and BlackWhite Wage Differentials." Review of Economics and Statistics 68 (1): 41-47.

Lemieux, Thomas. 2008. "The Changing Nature of Wage Inequality." Journal of Population Economics 21 (1): 21-48.

Lillard, Dean R. and Philip P. DeCicca. 2001. "Higher Standards, More Dropouts? Evidence within and Across Time." Economics of Education Review 20 (5): 459-473.

Ludwig, Jens and Douglas L. Miller. 2007. "Does Head Start Improve Children's Life Chances? Evidence from a Regression Discontinuity Design." Quarterly Journal of Economics 122 (1): 159-208.

Lutz, Byron. 2011. "The End of Court-Ordered Desegregation." American Economic Journal: Economic Policy 3 (2): 130-168. 
Lyche, Cecilia S. 2010. Taking on the Completion Challenge. Paris: OECD.

McIntosh, Shelby. 2012. State High School Exit Exams: A Policy in Transition. Washington, DC: Center on Education Policy.

McLeod, Jane and Karen Kaiser. 2004. "Childhood Emotional and Behavior Problems and Educational Attainment." American Sociological Review 69 (5): 636-658.

Mechoulan, Stephane. 2011. "The External Effects of Black Male Incarceration on Black Females." Journal of Labor Economics 29 (1): 1-35.

Mincer, Jacob. 1958. "Investment in Human Capital and Personal Income Distribution." Journal of Political Economy 66: 281-302.

Mishel, Lawrence and Joydeep Roy. 2006. Rethinking High School Graduation Rates and Trends. Washington, D.C.: Economic Policy Institute.

Mulligan, Casey B. and Yona Rubinstein. 2008. "Selection, Investment, and Women's Relative Wages Over Time." Quarterly Journal of Economics 123 (3): 1061-1110.

Murnane, Richard J., John B. Willett, and John H. Tyler. 2000. "Who Benefits from Obtaining a GED? Evidence from High School and Beyond." Review of Economics and Statistics 82 (1): 23-37.

National Commission on Excellence in Education. 1983. A Nation at Risk: The Imperative for Educational Reform. Washington, D.C.: U.S. Department of Education.

Neal, Derek. 2004. "The Measured Black-White Wage Gap among Women is Too Small." Journal of Political Economy 112 (1): S1-28.

Neal, Derek A. and William R. Johnson. 1996. "The Role of Premarket Factors in Black-White Wage Differences." Journal of Political Economy 104 (5): 869-895.

Nelson, Charles A. and Margaret Sheridan. 2011. "Lessons from Neuroscience Research for Understanding Causal Links between Family and Neighborhood Characteristics and Educational Outcomes." In Whither Opportunity: Growing Inequality, Schools, and Children's Life Chances, edited by Greg J. Duncan and Richard J. Murnane. New York: Russell Sage Foundation.

Nord, Christine, Shep Roey, Robert Perkins, Marsha Lyons, Nita Lemanski, Janis Brown, and Jason Schuknecht. 2011. The Nation's Report Card: America's High School Graduates. Washington, DC: U.S. Department of Education, National Center for Education Statistics. U.S. Government Printing Office.

OECD. 2007. Education at a Glance 2007: OECD Indicators. 
— . 2012. Education at a Glance 2012: OECD Indicators. Paris: OECD Publishing.

Office of Juvenile Justice and Delinquency Prevention. 2011. OJJDP Statistical Briefing Book. Washington, DC: OJJDP.

O'Neill, June. 1990. "The Role of Human Capital in Earnings Differences between Black and White Men." Journal of Economic Perspectives 4: 25-45.

Oreopoulos, Philip. 2009. "Would More Compulsory Schooling Help Disadvantaged Youth? Evidence from Recent Changes to School-Leaving Laws." In The Problems of Disadvantaged Youth: An Economics Perspective, edited by Jonathan Gruber, 85-112. Chicago: University of Chicago Press.

Oreopoulos, Philip. 2007. "Do Dropouts Drop Out Too Soon? Wealth, Health and Happiness from Compulsory Schooling." Journal of Public Economics 91 (11-12): 2213-2229.

Page, Lindsay C. 2012. "Principal Stratification as a Framework for Investigating Mediational Processes in Experimental Settings." Journal of Research on Educational Effectiveness, 5: 215-244.

Patterson, Margaret Becker, Jizhi Zhang, Wei Song, and Anne Guison-Dowdy. 2010. Crossing the Bridge: GED Credentials and Postsecondary Educational Outcomes. Year One Report. Washington, D.C.: GED Testing Service.

Powell, Arthur G., Eleanor Farrar, and David K. Cohen . 1985. The Shopping Mall High School : Winners and Losers in the Educational Marketplace. Boston: Houghton Mifflin.

Quint, Janet, Howard S. Bloom, Alison Rebeck Black, and LaFleur Stephens. 2005. The Challenge of Scaling Up Educational Reform: Findings and Lessons from First Things First . New York: MDRC.

Reardon, Sean F., Allison Atteberry, Nicole Arshan, and Michal Kurlaender. 2010. "Effects of the California High School Exit Exam Requirement on Student Persistence, Achievement, and Graduation." Working Paper, Stanford University.

Reardon, Sean and Michal Kurlaender. 2009. Effects of the California High School Exit Exam on Student Persistence, Achievement, and Graduation. Stanford, CA: PACE Policy Brief.

Reynolds, Arthur J., Judy A. Temple, Suh-Ruu Ou, Irma A. Arteaga, and Barry A. B. White. 2011. "School-Based Early Childhood Education and Age-28 Well-being: Effects by Timing, Dosage, and Subgroups." Science 333 (6040): 360-364.

Rodriguez-Planas, Nuria. 2012. "Longer-Term Impacts of Mentoring, Educational Services, and Learning Incentives: Evidence from a Randomized Trial in the United States." American Economic Journal: Applied Economics 4 (4): 121-139. 
Roy, Joydeep and Lawrence Mishel. 2008. "Using Administrative Data to Estimate Graduation Rates: Challenges, Proposed Solutions and their Pitfalls." Education Policy Analysis Archives 16.

Rumberger, Russell W. 2011. Dropping Out : Why Students Drop Out of High School and what can be done about it. Cambridge, Mass.: Harvard University Press.

Schwerdt, Guido and Martin R. West. in press. "The Impact of Alternative Grade Configurations on Student Outcomes through Middle and High School." Journal of Public Economics.

Seastrom, Marilyn M., Chris Chapman, Robert Stillwell, Daniel McGrath, Pia Peltola, Rachel Dinkes, and Zeyu Xu. 2006. User's Guide to Computing High School Graduation Rates, Volume 1: Review of Current and Proposed Graduation Indicators . Washington, DC: U.S. Department of Education, National Center for Education Statistics.

Snipes, Jason C., Glee Ivory Holton, Fred Doolittle, and Laura Sztejnberg. 2006. Striving for Student Success:

the Effect of Project GRAD on High School Student Outcomes in Three Urban School Districts . New York: MDRC.

Snyder, Thomas D. and Sally A. Dillow. 2012. Digest of Education Statistics 2011. Vol. NCES 2012-001. Washington, D.C.: National Center for Education Statistics, Institute of Education Sciences, U.S. Department of Education.

Steinberg, Laurence. 2010. "A Behavioral Scientist Looks at the Science of Adolescent Brain Development." Brain and Cognition 72: 160-164.

Stillwell, Robert, Jennifer Sable, and Chris Plotts. 2011. Public School Graduates and Dropouts from the Common Core of Data: School Year 2008-09. Washington, D.C.: National Center for Education Statistics, Institute of Education Sciences, U.S. Department of Education.

Supovitz, Jonathan A. 2009. "Can High Stakes Testing Leverage Educational Improvement?" Journal of Educational Change 10 (2): 211-227.

Swanson, Christopher B. 2003. Keeping Count and Losing Count: Calculating Graduation Rates for all Students Under NCLB Accountability. Washington D.C.: The Urban Institute Education Policy Center.

Tyler, John H., Richard J. Murnane, and John B. Willett. 2000. "Estimating the Labor Market Signaling Value of the GED." Quarterly Journal of Economics 115 (2): 431-468.

U.S. Department of Education. 2008. No Child Left Behind: High School Graduation Rate NonRegulatory Guidance. Washington, D.C.: U.S. Department of Education.

U.S. Department of Health and Human Services. 2010. Head Start Impact Study: Final Report. Washington, DC: Department of Health and Human Services. 
Ventura, Stephanie J., Sally C. Curtin, Joyce C. Abma, and Stanley K. Henshaw. 2012. Estimated Pregnancy Rates and Rates of Pregnancy Outcomes for the United States, 19902008, National Vital Statistics Reports, V. 60, no. 7. Washington, DC: Centers for Disease Control and Prevention, U.S. Department of Health and Human Services.

Warren, John R., Krista N. Jenkins, and Rachael Kulick. 2006. "High School Exit Examinations and State-Level Completion and GED Rates, 1975-2002." Educational Evaluation and Policy Analysis 28: 131-152.

Warren, John Robert and Andrew Halpern-Manners. 2009. "Measuring High School Graduation Rates at the State Level: What Difference does Methodology make?" Sociological Methods \& Research 38 (1): 3-37.

Warren, Robert and Andrew Halpern-Manners. 2007. "Is the Glass Emptying Or Filling Up? Reconciling Divergent Trends in High School Completion and Dropout." Educational Researcher 36 (6): 335-343.

Weiland, Christina and Hirokazu Yoshikawa. in press. "Impacts of a Prekindergarten Program on Children's Mathematics, Language, Literacy, Executive Function, and Emotional Skills." Child Development. 